\title{
Impact of Intermittent Screening and Treatment for Malaria among School Children in Kenya: A Cluster Randomised Trial
}

\author{
Katherine E. Halliday ${ }^{1}$, George Okello ${ }^{2}$, Elizabeth L. Turner ${ }^{3}$, Kiambo Njagi ${ }^{4}$, Carlos Mcharo ${ }^{5}$, \\ Juddy Kengo ${ }^{5}$, Elizabeth Allen ${ }^{6}$, Margaret M. Dubeck ${ }^{7}$, Matthew C. H. Jukes ${ }^{8}$, Simon J. Brooker ${ }^{1,9}$
}

1 Faculty of Infectious and Tropical Diseases, London School of Hygiene \& Tropical Medicine, London, United Kingdom, 2 Health Systems and Social Science Research Group, Kenya Medical Research Institute-Wellcome Trust Research Programme, Kilifi, Kenya, 3 Department of Biostatistics and Bioinformatics and Duke Global Health Institute, Duke University, Durham, North Carolina, United States of America, 4 Division of Malaria Control, Ministry of Public Health \& Sanitation, Nairobi, Kenya, $\mathbf{5}$ Health and Literacy Intervention Project, Ukunda, Kenya, 6 Faculty of Epidemiology and Population Health, London School of Hygiene \& Tropical Medicine, London, United Kingdom, 7 Department of Teacher Education, College of Charleston, South Carolina, United States of America, 8 Graduate School of Education, Harvard University, Cambridge, Massachusetts, United States of America, 9 Malaria Public Health Department, Kenya Medical Research Institute-Wellcome Trust Research Programme, Nairobi, Kenya

\begin{abstract}
Background: Improving the health of school-aged children can yield substantial benefits for cognitive development and educational achievement. However, there is limited experimental evidence of the benefits of alternative school-based malaria interventions or how the impacts of interventions vary according to intensity of malaria transmission. We investigated the effect of intermittent screening and treatment (IST) for malaria on the health and education of school children in an area of low to moderate malaria transmission.

Methods and Findings: A cluster randomised trial was implemented with 5,233 children in 101 government primary schools on the south coast of Kenya in 2010-2012. The intervention was delivered to children randomly selected from classes 1 and 5 who were followed up for 24 months. Once a school term, children were screened by public health workers using malaria rapid diagnostic tests (RDTs), and children (with or without malaria symptoms) found to be RDT-positive were treated with a six dose regimen of artemether-lumefantrine $(\mathrm{AL})$. Given the nature of the intervention, the trial was not blinded. The primary outcomes were anaemia and sustained attention. Secondary outcomes were malaria parasitaemia and educational achievement. Data were analysed on an intention-to-treat basis. During the intervention period, an average of $88.3 \%$ children in intervention schools were screened at each round, of whom $17.5 \%$ were RDT-positive. $80.3 \%$ of children in the control and $80.2 \%$ in the intervention group were followed-up at 24 months. No impact of the malaria IST intervention was observed for prevalence of anaemia at either 12 or 24 months (adjusted risk ratio [Adj.RR]: 1.03, 95\% Cl 0.93-1.13, $p=0.621$ and Adj.RR: $1.00,95 \% \mathrm{Cl} 0.90-1.11, p=0.953$ ) respectively, or on prevalence of $P$. falciparum infection or scores of classroom attention. No effect of IST was observed on educational achievement in the older class, but an apparent negative effect was seen on spelling scores in the younger class at 9 and 24 months and on arithmetic scores at 24 months.

Conclusion: In this setting in Kenya, IST as implemented in this study is not effective in improving the health or education of school children. Possible reasons for the absence of an impact are the marked geographical heterogeneity in transmission, the rapid rate of reinfection following AL treatment, the variable reliability of RDTs, and the relative contribution of malaria to the aetiology of anaemia in this setting.
\end{abstract}

Trial registration: http://www.ClinicalTrials.gov. NCT00878007

Please see later in the article for the Editors' Summary.

Citation: Halliday KE, Okello G, Turner EL, Njagi K, Mcharo C, et al. (2014) Impact of Intermittent Screening and Treatment for Malaria among School Children in Kenya: A Cluster Randomised Trial. PLoS Med 11(1): e1001594. doi:10.1371/journal.pmed.1001594

Academic Editor: Lorenz von Seidlein, Mahidol-Oxford Tropical Medicine Research Unit, Thailand

Received August 16, 2013; Accepted December 6, 2013; Published January 28, 2014

Copyright: (C) 2014 Halliday et al. This is an open-access article distributed under the terms of the Creative Commons Attribution License, which permits unrestricted use, distribution, and reproduction in any medium, provided the original author and source are credited.

Funding: This work was supported by grants from the International Initiative for Impact Evaluation, the Partnership for Child Development, and the Development Impact Evaluation Initiative as part of the Malaria Impact Evaluation Program of the World Bank. GO is supported by a Wellcome Trust Masters Training Fellowship (092765) and SJB is supported by a Wellcome Trust Senior Fellowship in Basic Biomedical Science (098045). The funders had no role in the study design, data collection, data analysis, data interpretation, or writing of the report. The corresponding author had full access to all the data in the study and had final responsibility for the decision to submit for publication.

Competing Interests: The authors have declared that no competing interests exist.

Abbreviations: Adj.MD, adjusted mean difference; Adj.RR, adjusted risk ratio; $\mathrm{AL}$, artemether lumefantrine; GEE, generalized estimating equations; $\mathrm{Hb}$ haemoglobin; ICC, intraclass correlation coefficient; IPT, intermittent preventive treatment; IQR, inter-quartile range; IST, intermittent screening and treatment; RDT, rapid diagnostic test; SD, standard deviation; SES, socioeconomic status.

* E-mail: katherine.halliday@Ishtm.ac.uk 


\section{Introduction}

In many malaria endemic countries, successful control programmes have recently reduced the level of malaria transmission [1-3], and as a consequence, immunity to malaria is acquired more slowly and the burden of clinical malaria is shifting from the very young to older children $[4,5]$. Recent success in malaria control has also prompted a renewed emphasis on malaria elimination, leading to a shift in focus from targeting only clinical malaria to also identifying and treating asymptomatic malaria parasitaemia [1,6]. Infection rates are typically highest among school-aged children [7,8], who, due to recent improvements in primary school access, are increasingly enrolled in school $[9,10]$. Tackling such parasitaemia, whether or not it results in clinical disease, is important for two reasons. First, an increasing body of evidence is showing that chronic untreated Plasmodium infections can negatively affect children's health [11,12] and cognitive function [13-15], including sustained attention [16], and ultimately, their educational achievement $[17,18]$. Second, with the move towards elimination in low-moderate transmission settings $[19,20]$, there is a need to tackle untreated reservoirs of infection, to which school children are important contributors $[21,22]$. Yet, surprisingly, there remains a lack of consistent policy and technical guidance [23] on which interventions can reduce the burden of malaria among school children and which can cost-effectively be delivered through existing school systems.

Previous studies have highlighted the beneficial impact of school-based intermittent preventive treatment (IPT) on health and cognitive function in high [24] and high, seasonal [25] malaria transmission settings. However, the recent withdrawal of the primary drugs for IPT, sulphadoxine-pyrimethamine (SP) and amodiaquine (AQ), in many east African countries, precluded further investigation of IPT using SP+AQ. A possible alternative to IPT is intermittent screening and treatment (IST), whereby individuals are periodically screened for Plasmodium infection using a rapid diagnostic test (RDT) and those infected (whether symptomatic or not) are treated with a full course of first-line drug treatment, artemether-lumefantrine (AL). The potential of IST was first highlighted by modelling work [26,27], and its comparable efficacy to IPT in antenatal care [28] has been evaluated, although a recent trial in Burkina Faso indicated no impact of IST on community-wide malaria transmission [29]. This paper reports the results of a cluster randomised trial investigating the impact of IST in schools on health and education outcomes in school children in a low-moderate transmission setting on the south coast of Kenya [30].

\section{Methods}

The original protocol for the trial (Protocol S1) and the supporting CONSORT checklist (Checklist S1) are provided as supporting information. Trial instruments and data are available on the World Bank Microdata catalogue at: http://microdata. worldbank.org/index.php/catalog/671.

\section{Ethics Statement}

The study was approved by the Kenya Medical Research Institute and National Ethics Review Committee (SSG number 1543), the London School of Hygiene \& Tropical Medicine Ethics Committee (5503), and the Harvard University Committee on the Use of Human Subjects in Research (F17578-101). Prior to the randomisation, meetings were held with community and school leaders and parents/guardians in each school to explain the study objectives and procedures. Parents/guardians of all children in classes 1 and 5 were requested to provide individual written informed consent and they were given the option to withdraw their child from the study at any time. Prior to every IST round or assessment, the procedures were explained to the children and they were required to provide verbal assent. An independent data monitoring committee reviewed the trial protocol, data analysis plan, and preliminary results.

\section{Study Area and Population}

The trial was conducted from January 2010 to March 2012 in Kwale and Msambweni districts on the south Kenyan coast (Figure 1). Malaria transmission in the area is moderate and perennial with seasonal peaks following the two rainy seasons (April-July and September-November) [31]. The primary malaria vectors are Anopheles gambiae s.l. and A. funestus [32,33]. Intensity of malaria transmission has been declining in recent years: school surveys conducted in 2010 reported prevalences of $P$. falciparum of $9 \%-24 \%$ [34,35], compared to $64 \%$ in 1998 [32]. Overall reported net use in the region is high, with the communities having benefited from universal coverage campaigns. During the two-year trial period, albendazole was delivered through households as part of the national lymphatic filariasis campaign in 2011, although coverage was not extensive and praziquantel was delivered to schools in the area in June 2011. The vast majority of the population in these districts belong to the Mijikenda ethnic group, with Digo and Duruma the predominant subgroups [36]. The region is primarily rural with subsistence farming of maize and cassava practiced by many of the communities, although titanium mining has recently become an important source of employment. In economic and educational terms, the districts are ranked the seventh poorest in Kenya and consistently have some of the worst performing schools in the national school examinations [37].

Kwale District has 85 schools across four zones, and in two of these an alternative literacy intervention study was underway. Therefore only 20 schools from Mkongani and Shimba Hills zones were included in our study, allowing the two interventions to proceed without leakage. In Msambweni District 81 of the 112 schools were selected, with schools in Lunga Lunga and Mwereni zones greater than $70 \mathrm{~km}$ away from the project office excluded because of logistical considerations in visiting them.

\section{Study Design}

The study was designed as a factorial cluster randomised trial to investigate the impact of two interventions: (i) the impact of schoolbased IST for malaria on the health, sustained attention, and education of school children, and (ii) the impact of a literacy intervention on education. In order to evaluate the potential interaction between the two interventions, schools were randomised to one of four groups, receiving either: (i) IST alone; (ii) the literacy intervention alone; (iii) both interventions combined; or (iv) control group where neither intervention was implemented (Figure 2). The study was not blinded. Because of the factorial design of the trial and lack of interaction detected (interaction effect $p$-values of $0.45,0.26$, and 0.60 for the three key literacy outcomes) between the two interventions in class 1 where both were implemented, we report the results of the interventions separately. Only the IST intervention results are reported in this paper. The results of the literacy intervention will be reported in a separate paper targeting an education research audience as the literacy intervention was focused purely on enhanced English and Swahili literacy instruction and was not intended to have an impact on health. 

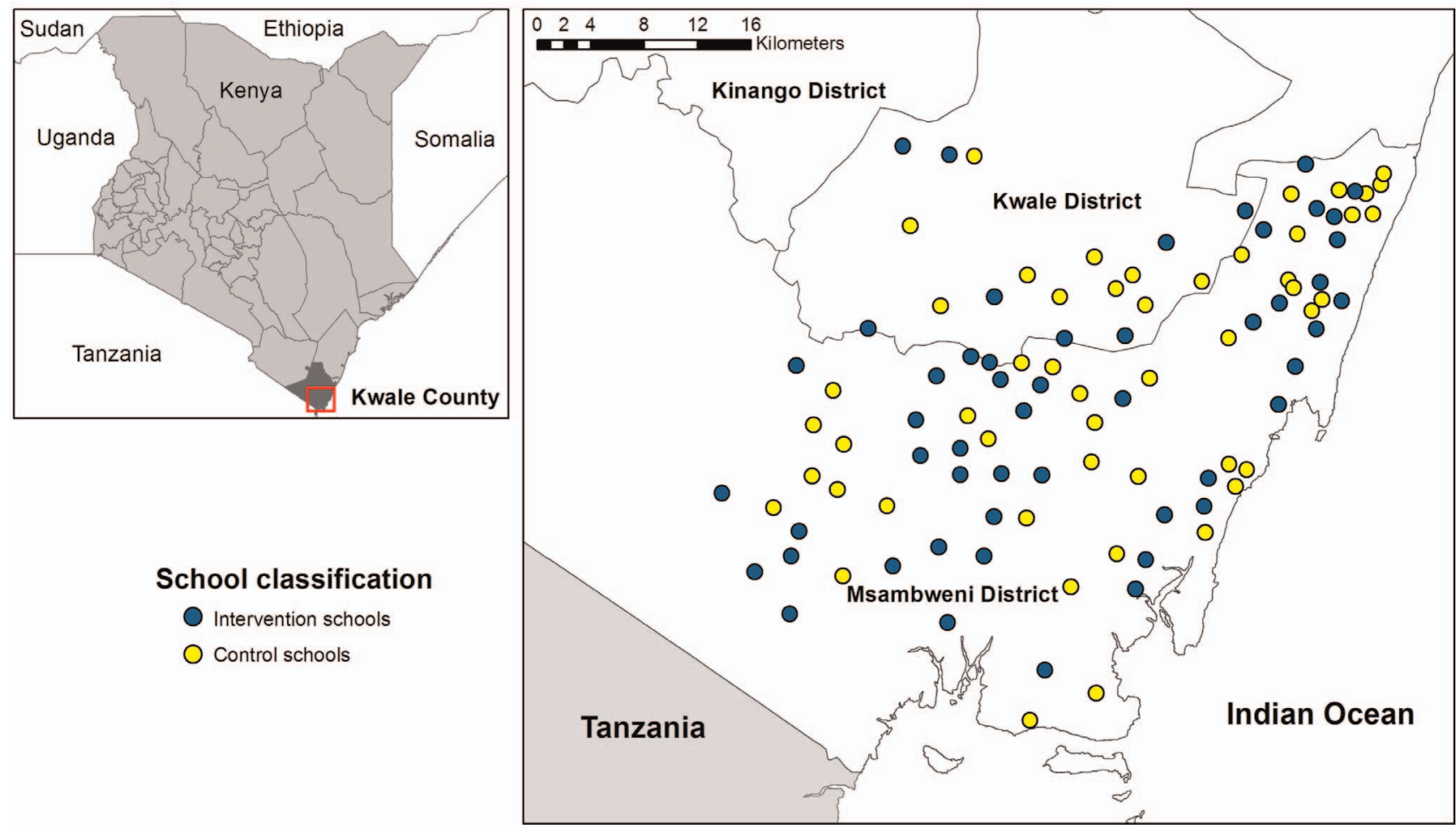

Figure 1. Map of the study area and schools. Schools assigned to the IST intervention are shown in blue and schools assigned to the control group are shown in yellow. Insert shows the location of the study site in Kenya. doi:10.1371/journal.pmed.1001594.g001

Recruitment and baseline sample collection were conducted in January-March 2010 using children randomly selected from classes 1 (age range: 5-15 years) and 5 (age range: 8-20 years). Both classes received the IST intervention, but the literacy intervention was targeted only to children in class 1 and as they advanced to class 2, as it focused on the initial stages of literacy acquisition. Education outcome measures were assessed in the same children at 9 and 24 months and health outcome measures at 12 and 24 months. Full details of the eligibility, randomisation, intervention procedures, and baseline results have been presented elsewhere $[30,35]$. The study is registered with ClinicalTrials.gov, NCT00878007.

\section{Sample Size}

The sample size was based on methods designed for cluster randomised trials and assumed that 101 eligible schools would be randomised to the four intervention groups, with an average of 50 children per school. On the basis of data collected previously in the study area, the baseline prevalence of anaemia was assumed to be $20 \%$ and the coefficient of variation (CV) 0.2 [30]. In order to detect a $25 \%$ reduction in the prevalence of anaemia between the two groups, based on previous work in Kenya [24], the sample size required to give a study with a power of $80 \%$ at a two-sided significance level of $5 \%$, was a total of 27 schools in each arm with 50 children per school. A sample size of 101 schools with 25 children per class (i.e., analysing classes 1 and 5 separately) will enable us to detect, with $80 \%$ power and $5 \%$ significance, an approximate difference of 0.2 standard deviations (SDs) between arms of the trial in educational achievement (assuming an intraclass correlation coefficient [ICG] of 0.2 and a pre-post correlation of 0.7 ), and a difference of approximately $0.15 \mathrm{SD}$ in tests of sustained attention (assuming an ICC of 0.1 and a pre post correlation of 0.7) [24]. The increased number of schools required for the sustained attention and educational achievement outcomes provided greater power $(97 \%)$ to detect a $25 \%$ reduction in the prevalence of anaemia, or alternatively $85 \%$ power to detect a $20 \%$ reduction.

\section{Randomisation}

The 101 schools were randomised in two stages (Figure 2), with each stage conducted during a public ceremony. In Kenya, schools are aggregated into sets of between three and six closely located schools, which regularly meet and share information, supported by a Ministry of Education Teacher Advisory Centre tutor. Our 101 study schools formed 24 of these sets of schools, which were randomised either to receive the literacy intervention or to serve as the literacy control. Randomisation of these sets of schools was stratified by (i) set size, to ensure equal numbers of schools in the experimental groups, and (ii) average primary school leaving exam scores of the school sets, to balance the two study groups for school achievement. This randomisation procedure was designed to minimize contamination of the literacy intervention methods across the study groups. In stage two, the IST intervention was randomly allocated at the level of the school, with the 101 schools re-stratified by (i) literacy intervention group assignment and (ii) quintiles of average school exam scores, producing ten strata overall.

\section{Enrolment}

At enrolment, children's height and weight were measured, axillary temperature was digitally recorded, and finger-prick blood samples were obtained to prepare thin and thick blood films and to determine haemoglobin concentration $(\mathrm{Hb})$. Children known or suspected to be homozygous for sickle cell trait or pregnant were 


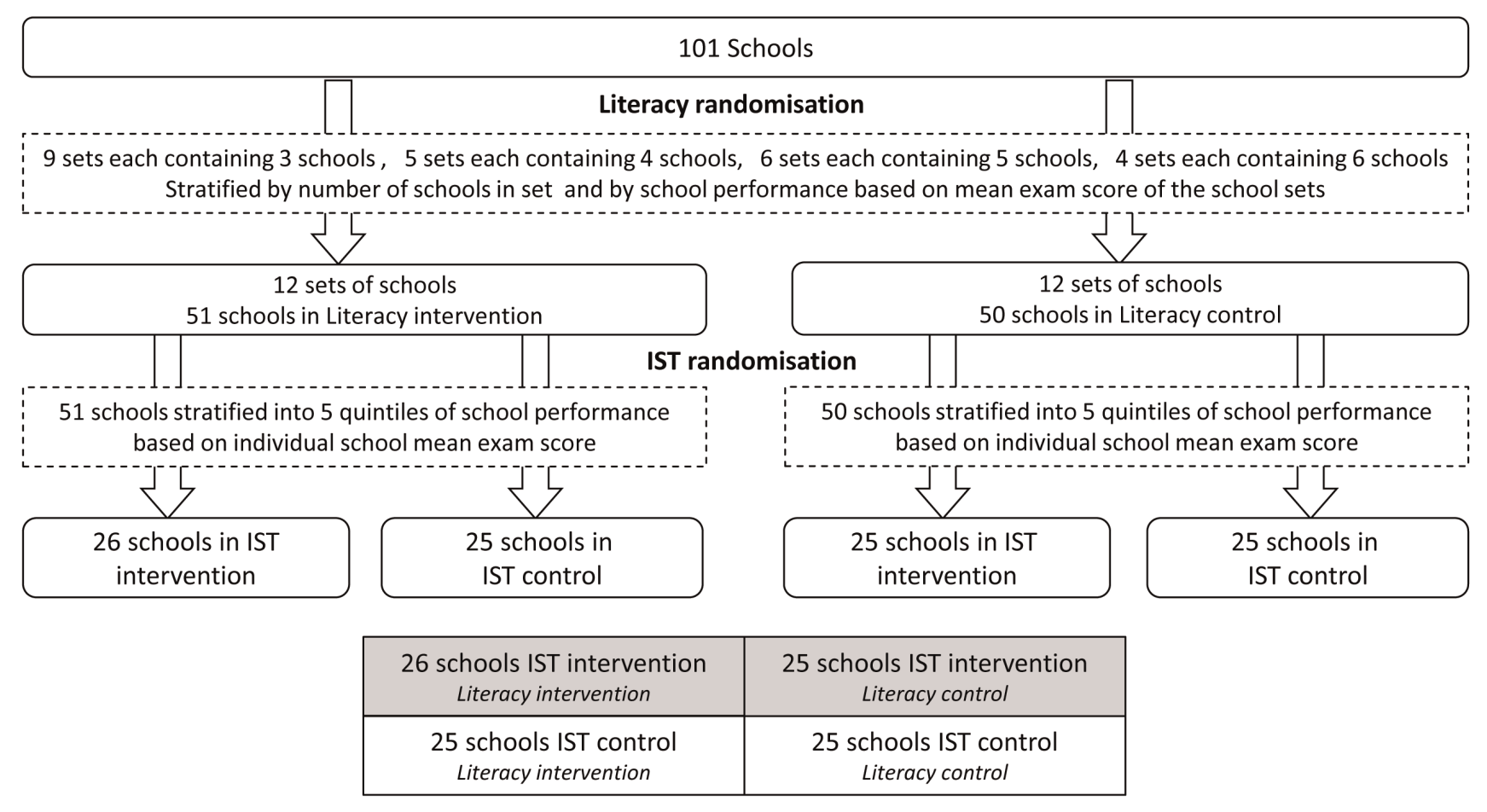

Figure 2. Study design diagram. This figure depicts the randomisation procedures. doi:10.1371/journal.pmed.1001594.g002

excluded. Any child found with $\mathrm{Hb}<80 \mathrm{~g} / \mathrm{l}$ was referred by the nurse to the nearest health facility for iron therapy, and any child found with $\mathrm{Hb}<50 \mathrm{~g} / \mathrm{l}$ was taken to the hospital for transfusion. Baseline parasitaemia was measured in the intervention group during the first round of screening but was not measured in the control group owing to the ethical constraints of testing for malaria but not treating children found to be infected in the control schools, which was of particular importance at baseline as the intervention involved screening of Plasmodium infection.

A questionnaire was administered to parents/guardians to record information on residence, family size, ownership of possessions, mosquito net use by them and their children, recent deworming of the child, house construction, and parental education level.

\section{Intervention}

IST was outlined as a possible strategy in the "Malaria-Free Schools Initiative," as part of the Kenya National Malaria Strategy 2009-2017 [38]. During IST, children were screened once a school term for malaria parasitaemia using an RDT (ParaCheck$P f$ device, Orchid Biomedical Systems), which is able to detect $P$. falciparum. Screening was conducted by laboratory technicians. Repeat visits were made to follow-up children absent on the day of screening. Children (with or without malaria symptoms) found to be RDT-positive were treated with a six dose regimen of $\mathrm{AL}$ (artemether $20 \mathrm{mg} /$ lumefantrine $120 \mathrm{mg}$, Coartem, Novartis) over three days. Doses of AL were based on weight, with children stratified into one of the four categories $(<15 \mathrm{~kg}, 15-24.9 \mathrm{~kg}, 25-$ $34.9 \mathrm{~kg}$, and $\geq 35 \mathrm{~kg}$ ). AL was given at a dose of $20 / 120 \mathrm{mg}$ to children $<15 \mathrm{~kg}, 40 / 240 \mathrm{mg}$ to children $15-24.9 \mathrm{~kg}, 60 / 360 \mathrm{mg}$ to children $25-34.9 \mathrm{~kg}$, and $80 / 480 \mathrm{mg}$ to those who weighed $\geq 35 \mathrm{~kg}$. Parents or older siblings of children were called and a nurse explained that their child was infected with malaria parasites and required treatment. Doses 1, 3, and 5 were given under direct observation at the school by the study nurses. Children were given milk and biscuits with the AL and observed for 30 minutes after drug administration. If vomiting occurred during this period, drugs were re-administered. If vomiting occurred on a second occasion, this was noted but the drugs were not given again. Such children were not excluded from the trial and they were eligible to receive drugs on the subsequent two days. The parents/older siblings or study children themselves if in the older classes were given doses 2, 4, and 6 each day for evening administration and provided with instructions on treatment. Children absent from school on days two or three of treatment were followed up at their home by the nurse, and provided with the doses. Supervised treatment was defined as nurses administering and directly observing doses 1,3 , and 5 taken on three consecutive mornings in the school and recording doses 2 and 4 reported by the child as having been taken the previous evenings. No direct confirmation of whether dose 6 was taken was recorded by the nurse. The record of supervised treatment was used as a proxy for compliance. Five rounds of screening and treatment were implemented. The first round was conducted alongside baseline health assessments in March 2010, the second round in July 2010, the third in September 2010, the fourth in March 2011, and the final round in October 2011.

Adverse events were monitored by the study team for 24 hours after each treatment, and a further 28 days thereafter using a passive surveillance system in schools. Travel costs were reimbursed and treatment charges waived. Adverse experiences were monitored until the event was cured or had stabilised. Agranulocytosis and hepatotoxicity were not assessed because of logistical constraints.

\section{Follow-up}

Cross sectional health surveys were carried out at 12 and 24 months. During these surveys, temperature, weight, and height 
were measured and a finger-prick blood sample was collected for determination of malaria parasitaemia and $\mathrm{Hb}$. Children with an axillary temperature $\geq 37.5^{\circ} \mathrm{C}$ were tested using an RDT, providing an on-the-spot diagnosis for malaria, and treatment was administered as per national guidelines.

\section{Laboratory Methods}

$\mathrm{Hb}$ was measured using a portable haemoglobinometer (Hemocue). Thick and thin blood films were stained with Giemsa, asexual parasites were counted against 200 white blood cells (WBCs), and parasite density was estimated assuming an average WBC count of 8,000 cells/ $\mu \mathrm{l}$. A smear was considered negative after reviewing 100 high-powered fields. Thin blood smears were reviewed for species identification. All blood slides were read independently by two microscopists who were blinded to group allocation. Discrepant results were resolved by a third microscopist.

\section{Attention and Educational Achievement}

Tests of sustained attention and educational achievement were administered at baseline, 9 months, and 24 months. Sustained attention was a primary outcome, assessed through the code transmission test, adapted from the TEA-Ch (Tests of everyday attention for children) battery [39]. A recorded list of digits is read aloud and children are required to listen for a code-two consecutive occurrences of the number 5-and then record the number(s) that preceded the code. To avoid floor effects, (in which the assessment is too challenging to establish the range of abilities in the target population), a simpler measure of sustained attention - the pencil tap test [40] — was used at baseline for the younger cohort. Children were required to tap a pencil on the desk a predetermined number of times in response to the assessor's taps. The secondary outcome of educational achievement was measured through tests of literacy and numeracy. Literacy was assessed through group administered English spelling tests, adapted from PALS (Phonological Awareness Literacy Screening) [41], with the younger classes asked to spell five three-letter words and credit given for phonetically acceptable choices for each letter and the older classes asked to spell 25 words with credit given for correctly spelling the features and sound combinations of the word. Numeracy assessments involved an oral test of basic arithmetic for younger children at baseline and 9-month follow-up and written arithmetic at 24-month follow-up and a written arithmetic test throughout for older children. All educational assessments were piloted prior to use in the baseline and follow-up evaluations. During piloting the assessments were conducted under the same assessment conditions on two occasions a week apart, with the correlation between the scores at the two time points providing a reliability score. The inclusion criteria for the tests used in this trial was a Cronbach's alpha correlation of 0.7 or above, indicating a well constructed test with consistent administration.

The educational assessments were conducted separately to the health assessment both for logistical reasons and so as not to cause bias during the educational assessments due to apprehension of the finger-prick. The education assessments preceded the latter by an average of a week at baseline and 24-month follow-up. However, during the first follow-up, the education assessments were conducted at the end of the school year (9 months) and the health assessments were conducted at end of a full year (12 months).

\section{Data Analysis}

Data were double-entered, consistency checks were performed, and all analysis was conducted using Stata software version 12.1. The pre-specified primary outcome measures were the prevalence of anaemia, defined according to age and sex corrected World Health Organization (WHO) thresholds: $\mathrm{Hb}<110 \mathrm{~g} / \mathrm{l}$ in children under 5 years; $<115 \mathrm{~g} / 1$ in children 5 to 11 years; $<120 \mathrm{~g} / \mathrm{l}$ in females 12 years and over and males 12 to 15 years old; and $<130 \mathrm{~g} / \mathrm{l}$ in males over 15 years, with no adjustment made for altitude [42] and sustained attention. The pre-specified secondary outcomes were the prevalence of $P$. falciparum and scores for spelling and arithmetic. Reported information on ownership of household assets and household construction was used to construct wealth indices using principal component analysis [43] and resulting scores were divided into quintiles. Anthropometric measurements were processed using the WHO Anthroplus Stata macro [44] to derive indicators of stunting, thinness, and underweight.

The analyses described here correspond to a pre-specified statistical analysis plan, approved by both the data monitoring committee and trial steering committee before any data were examined.

Baseline school and child characteristics, together with baseline measurements of the study outcomes, were summarized by study groups separately, with class-specific study outcomes reported separately by class. Counts and percentages were used for categorical variables. Means and standard deviations, or medians and the limits of the inter-quartile range (IQR), were reported for continuous variables. Coefficients of variation $(\mathrm{CVs})$ for the binary (health) outcomes and intraclass correlation coefficients (ICGs) for the continuous (cognitive and education) outcomes were calculated from the baseline measures using appropriate formulae [45].

The effectiveness of the IST intervention was assessed using generalized estimating equations (GEE) with robust standard errors and an exchangeable correlation matrix to allow for clustering within schools. All main analyses used the intention-totreat principle whereby children were analyzed in the intervention group that they were assigned to, even if the child moved schools or did not fully comply. The primary pre-specified analysis adjusted for age (as a continuous variable), sex, and the baseline measure of the outcome, except for baseline $P$. falciparum, which was not measured in the control schools. As randomisation of schools to the IST intervention was stratified on the basis of both literacy intervention assignment and school mean exam score (Figure 2), all adjusted analyses presented account for these two stratification factors. Data for classes 1 and 5 combined were used for the health outcome analyses. However, as different assessments were administered for classes 1 and 5 for the evaluation of attention (e.g., pencil tap for class 1 and code transmission for class 5), literacy, and numeracy outcomes, analyses were conducted for each class separately. Separate GEE analyses were conducted for the first and second follow-ups. No formal adjustment was made for multiple testing, therefore $p$-values should be interpreted with due caution. However, as specified in the statistical analysis plan, formal testing was restricted to two primary and three secondary pre-specified outcomes.

For comparison purposes, we also obtained estimates from an unadjusted model that did not adjust for baseline outcome measures, child characteristics, or study design (literacy group and mean school-exam score) and hence retained all study children assessed at follow-up regardless of whether they had baseline measures. Secondary analyses were conducted additionally adjusting for stunting, school-feeding programme, and socioeconomic status (SES) on top of the pre-specified variables. These additional adjustments had no notable impact on the effect estimates and are not presented.

In order to gain power and account for missing data, random effects models, using a likelihood-based approach, were fitted to 
the one-year and two-year follow-up data simultaneously (Tables S1, S2, S3, S4, S5, S6, S7; Text S1). Additional sensitivity analyses were conducted to examine intervention effects when children who had transferred from their original school were excluded from the analyses (Table S8).

\section{Role of the Funding Source}

The funders had no role in the study design, data collection, data analysis, data interpretation, or writing of the report. The corresponding author had full access to all the data in the study and had final responsibility for the decision to submit for publication.

\section{Results}

\section{Trial Profile and Baseline Data}

One hundred and one schools were randomised to one of the two study groups (Figure 3). In total, 7,337 children aged between 5 and 20 years (median: 10 years and IQR: 8-13 years) were randomly selected in January 2010 of which 5,772 (78.7\%) parents consented, with no real differences found between groups in terms of percentage of parents refusing and not attending the meetings. Overall, 5,233 children were initially enrolled, of which 5,176 $(98.9 \%)$ children were eligible for follow-up after the baseline assessments. Characteristics of the children included in each of the study groups are shown in Table 1 . The numbers of children per school ranged from 18 to 58 but overall were well balanced between groups (control: median, 52; IQR, 50-54 and intervention: median, 53; IQR, 50-55). A difference in percentage of children unavailable for the baseline health surveys was observed between the groups with $5.1 \%$ and $10.1 \%$ unavailable in the control and intervention groups, respectively (Figure 3).

Children in the two study groups were broadly similar in regard to age, sex, anthropometric indices, bednet use, and household characteristics, with some slight apparent differences in school size and SES (Table 1). The primary outcomes, anaemia and educational measures, were also similar between groups at baseline; anaemia prevalence was $45.2 \%$ and $45.5 \%$ in control and intervention groups, respectively. The prevalence of $P$. falciparum, assessed only in the intervention group at baseline, was $12.9 \%$.

\section{Compliance with Screening and Treatment}

During the 24 months of intervention, an average of 2,340 children (88.4\% of eligible study children) in the 51 intervention schools were screened at each visit, of whom, on average $17.5 \%$ were RDT-positive (Table 2). Of the study children, $84.0 \%$ were screened at four or more IST rounds and $66.8 \%$ were screened at all five rounds. By the fifth screening round, 3.3\% children were lost due to withdrawal or death and a further $17.7 \%$ of children were lost due to out-migration. The percentage of children RDTpositive at each screening ranged from $14.8 \%$ to $19.2 \%$, with no distinct trend over time. Overall, 99.1\% of RDT-positive results led to treatment across the five screening rounds and $92.6 \%$ of these were recorded as receiving the fully supervised six-dose treatment regime (Table 2). There was an apparent decline in full supervision (a proxy for compliance) with time, falling from $96.9 \%$ at the first round to $81.7 \%$ at the fifth round. RDT performance, examined against a "gold standard" of expert microscopy, revealed consistently high specificity, greater than $90 \%$ at all rounds, whereas sensitivity was more variable ranging from $68.7 \%$ to $94.6 \%$ across surveys, with higher sensitivity observed during the wet season compared to the dry season (Table 2).

\section{Follow-up}

Of the 5,233 children enrolled initially, 4,446 (85.0\%) were included in the 12-month follow-up health survey and 4,201 $(80.3 \%)$ were included in the 24-month health survey (Figure 3). At 12 and 24 months, children lost to follow-up across both study arms were largely similar to children followed up (Tables S1 and S2), with slightly lower spelling scores in those children lost to follow-up across both groups and a higher proportion of children whose parents had no schooling in those lost to follow-up in the intervention schools. The prevalence of $P$. falciparum, in the intervention group, was lower in children lost to follow-up $(8.6 \%)$ compared to those followed-up (13.6\%) at both 12 and 24 months.

Overall, 4,656 $(89.0 \%)$ of children were included in the 9month follow-up education survey and 4,106 (78.5\%) in the 24month follow-up survey. Children unavailable for the follow-up educational surveys at 9 and 24 months were similar across the two study groups (Tables S4 and S5), with a slight imbalance in SES and parental education categories seen between children available and unavailable for the survey in the intervention group. Additionally, baseline prevalence of $P$. falciparum was lower in children lost to follow-up $(9.1 \%)$ compared to those followed-up $(13.3 \%)$ in the intervention arm.

As intention-to-treat analysis was performed, no adjustment was made for children transferring between schools and study groups at the follow-ups. Overall, 308 children were recorded as transferred by the end of the study. Of those, $46(0.9 \%), 71$ $(1.8 \%)$, and $308(5.9 \%)$ children were assessed in a different school from their initial enrolment school, at 9-month, 12-month, and 24month follow-ups, respectively. Sensitivity analysis excluding these transfers resulted in no change in direction or magnitude of results (Table S8).

\section{Effect of IST on Anaemia and P. falciparum Infection}

At 12-months follow-up, 2,148 children in the control schools and 2,298 in the intervention schools provided a finger-prick blood sample for $\mathrm{Hb}$ assessment, and at 24 months 2,027 and 2,174 children provided finger-prick samples in the control and intervention groups, respectively. There was no significant difference in the prevalence of anaemia between children in the two groups at 12- or 24-month follow-ups (adjusted risk ratio [Adj.RR]: 1.03, 95\% CI 0.93-1.13, $p=0.621$ and Adj.RR: 1.00, $95 \%$ CI $0.90-1.11, p=0.953$ ), respectively (Table 3 ); the same was observed in relation to mean $\mathrm{Hb}$. There was also no significant difference in the prevalence of $P$. falciparum between study groups at 12 or 24 months. Subgroup analysis of the impact of IST intervention on anaemia according to Plasmodium infection prevalence at baseline (using 12-month estimates for the control group as a proxy for baseline), demonstrated no differential impact by prevalence category $(<5 \%, 5 \%-19 \%$, and $20 \%+)$ at either follow-up. Similarly, no difference was seen when analysis was stratified, within the intervention group only, by numbers of treatments received across the study period (Tables S9 and S10).

\section{Effect of IST on Attention and Educational Achievement}

At both 9- and 24-months follow-up, there was no statistical difference in mean scores for sustained attention between study groups in either class with adjusted mean difference (Adj.MD): $-0.44,95 \% \mathrm{CI}-1.09$ to $0.21, p=0.180$ and Adj.MD: $0.28,95 \% \mathrm{CI}-0.23$ to $0.79, p=0.283$ for classes 1 and 5, respectively at the 24-month follow-up (Table 4). Similarly there was no significant difference between groups on scores for spelling in the older class at 9- and 24-month follow-ups (Adj.MD: $-0.31,95 \%$ CI -1.26 to $0.63, p=0.515$ and Adj.MD: 0.71, $95 \%$ CI -0.34 to $1.76, p=0.183$ ) nor for arithmetic at either follow-up (Table 5). 
101 schools. $n=13527$

MALARIA CONTROL GROUP

Randomly selected: $\quad \mathrm{N}=3487$

Refused/non response: $\mathrm{N}=76 / 643$

Consented: $\quad \mathrm{N}=2768$

STUDY CHILDREN AT START OF BASELINE: N=2523 (100\%)

50 Clusters

$50.5(6.9)$

$[18,58]$ [unavailable for survey: $\mathrm{N}=0(0.0 \%)$ ]

Baseline education assessments $\mathrm{N}=2523(100 \%)$

Class 1: $\mathrm{N}=1222$; Class 5: $\mathrm{N}=1301$

Withdrawn: $\mathrm{N}=21(0.8 \%)$; Deceased: $\mathrm{N}=0(0.0 \%)$

50 Clusters

47.5 (6.9)

$[16,55]$

Baseline health assessments $\mathrm{N}=2373$ (94.1\%) [unavailable for survey: $N=129$ (5.1\%)]

Class 1: $\mathrm{N}=1140$ Class 5: $\mathrm{N}=1233$

AVAILABLE FOR FOLLOW-UP : N=2502 (99.2\%)

Withdrawn: $\mathrm{N}=8$ (0.3\%); Deceased: $\mathrm{N}=1$ (0.0\%)

[unavailable for survey: $\mathrm{N}=235$ (9.3\%)]

50 Clusters

$45.2(7.0)$

$[16,54]$

FU1 educational assessments $\mathrm{N}=2258$ (89.5\%)

Class 1: $\mathrm{N}=1073$; Class 5: $\mathrm{N}=1185$

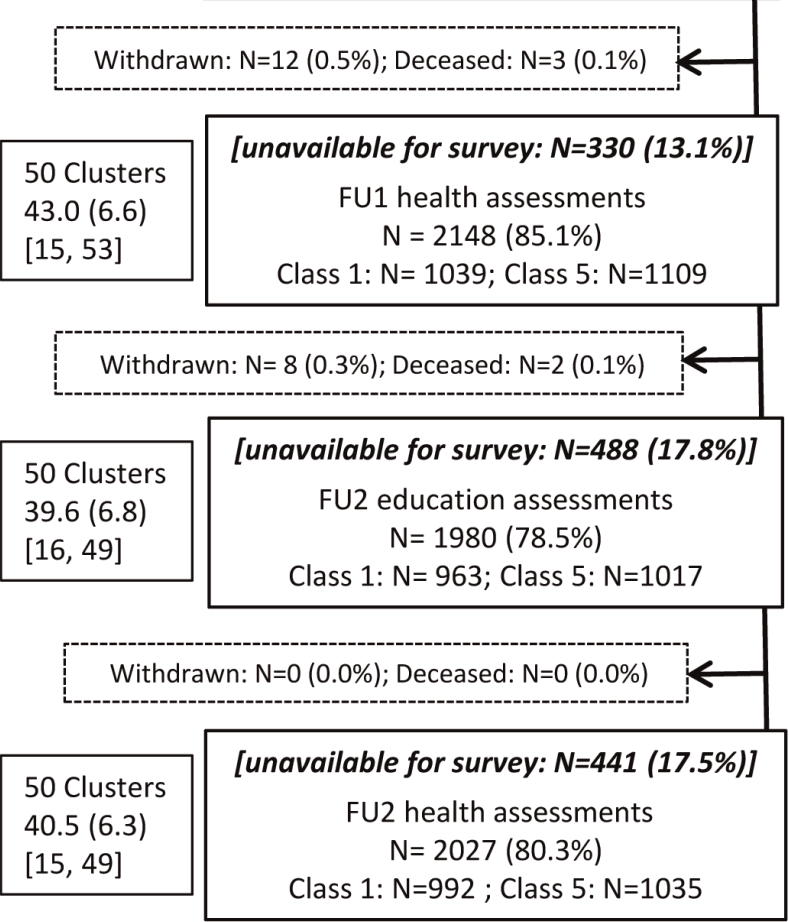

\begin{tabular}{|c|c|}
\hline \multirow{4}{*}{$\begin{array}{l}\text { Jan } \\
2010\end{array}$} & MALARIA INTERVENTION GROUP \\
\hline & Randomly selected: \\
\hline & Refused/non response: $\mathrm{N}=65 / 781$ \\
\hline & Consented: \\
\hline
\end{tabular}

STUDY CHILDREN AT START OF BASELINE: $\mathbf{N}=\mathbf{2 7 1 0}(100 \%)$

\begin{tabular}{l|c|l|}
\cline { 2 - 3 } & [unavailable for survey: $\mathrm{N}=\mathbf{3 4}(\mathbf{1 . 3 \%})]$ & 51 Clusters \\
$\mathbf{2 0 1 0}$ & Baseline education assessments & $52.5(3.6)$ \\
& $\mathrm{N}=2676(98.7 \%)$ & {$[41,58]$} \\
\hline
\end{tabular}

Withdrawn: $\mathrm{N}=36$ (1.3\%); Deceased: $\mathrm{N}=0(0.0 \%)$

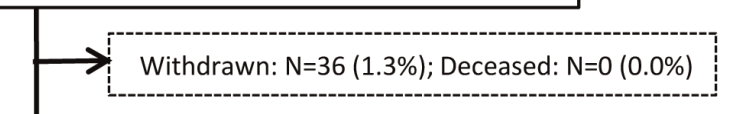

Mar

[unavailable for survey: $\mathrm{N}=274$ (10.1\%)]

Baseline health assessments $\mathrm{N}=2400(88.6 \%)$

Class 1: $N=1160 ;$ Class 5: $N=1240$

51 Clusters

$47.1(6.1)$

$[26,60]$

AVAILABLE FOR FOLLOW-UP : $\mathrm{N}=2674$ (98.7\%)

Withdrawn: $\mathrm{N}=28(1.0 \%)$; Deceased: $\mathrm{N}=0(0.0 \%)$

Oct

[unavailable for survey: $\mathrm{N}=\mathbf{2 4 8}(\mathbf{9 . 2 \% )}$

FU1 educational assessments $\mathrm{N}=2398$ (88.5\%)

Class 1: $\mathrm{N}=1164$; Class 5: $\mathrm{N}=1234$

51 Clusters

$47.0(4.1)$

$[36,55]$

Withdrawn: $\mathrm{N}=12$ (0.4\%); Deceased: $\mathrm{N}=3(0.1 \%)$

Feb/

Mar

2011

[unavailable for survey: $\mathrm{N}=333$ (12.3\%)]

FU1 health assessments $\mathrm{N}=2298(84.8 \%)$

Class 1: $\mathrm{N}=1126$; Class 5: $\mathrm{N}=1172$ $45.1(4.4)$ $[34,55]$

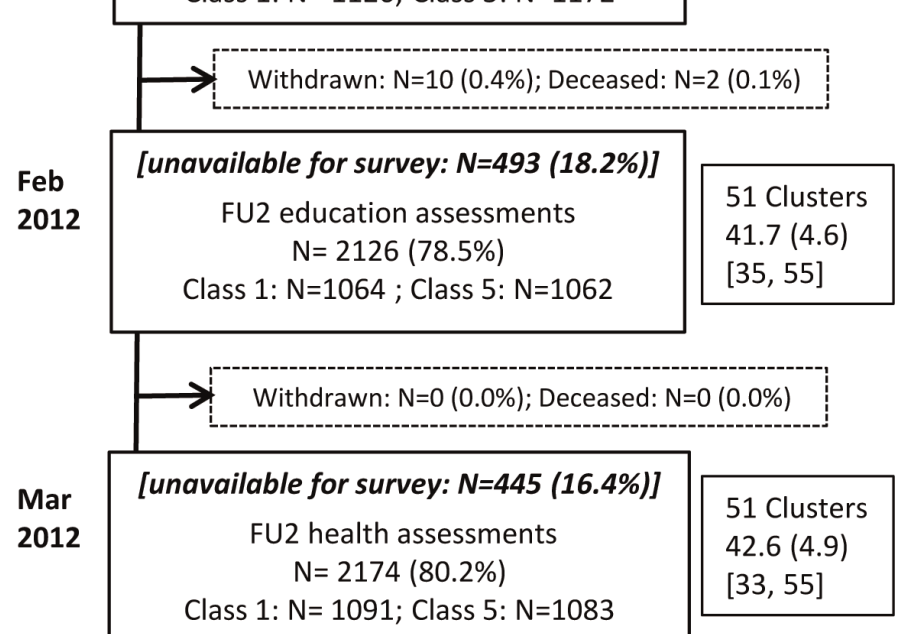

Figure 3. Trial profile. The flow of children and clusters in the 50 control 51 IST intervention groups at all assessment points throughout the twoyear study period. FU1 indicates follow-up 1 and FU2 indicates follow-up 2. Cluster size is presented as mean (SD) [min, max]. doi:10.1371/journal.pmed.1001594.g003 
Table 1. Baseline characteristics of 5,233 study children in the 50 control and 51 IST intervention schools.

\begin{tabular}{|c|c|c|c|}
\hline Characteristics; $n(\%)^{\mathrm{a}}$ & Measure/Subcharacteristic & Control & Intervention \\
\hline School characteristics $^{\text {b }}$ & & 50 schools & 51 schools \\
\hline Exam score & Mean (SD) & $223.4(27.7)$ & $225.8(29.0)$ \\
\hline School size & Median (IQR) [min, max] & $505(308,961)[85,4,891]$ & $568(389,692)[225,1,344]$ \\
\hline Enrolled class 1 & Mean (SD) [min, max] & $24.4(3.3)[10,30]$ & $25.8(1.5)[23,30]$ \\
\hline Enrolled class 5 & Mean (SD) [min, max] & $26.0(4.6)[8,30]$ & $27.3(3.3)[16,32]$ \\
\hline \multirow[t]{3}{*}{ School programmes } & Feeding & $22(44.0)$ & $27(52.9)$ \\
\hline & De-worming & $50(100.0)$ & $49(96.1)$ \\
\hline & Malaria control & $9(18.4)$ & $12(23.5)$ \\
\hline Child characteristics $^{b}$ & & 2,523 children & 2,710 children \\
\hline \multirow[t]{4}{*}{$\operatorname{Age}^{c}$} & Mean (SD) & $10.1(2.8)$ & $10.3(2.8)$ \\
\hline & $5-9$ & $1,041(41.2)$ & $1,069(39.5)$ \\
\hline & $10-12$ & $877(34.8)$ & $925(34.1)$ \\
\hline & $13-20$ & $605(24.0)$ & $716(26.4)$ \\
\hline Sex & Male & $1,257(49.8)$ & $1,319(48.7)$ \\
\hline \multirow[t]{3}{*}{ Child sleeps under net } & Usually & $1,668(67.3)$ & $1,682(63.1)$ \\
\hline & Treated net ${ }^{d}$ & 1,357 (83.3) & 1,308 (80.5) \\
\hline & Last night ${ }^{d}$ & 1,606 (96.3) & 1,609 (95.7) \\
\hline \multirow[t]{3}{*}{ Nutritional status } & Underweight & $266(27.0)$ & $231(23.9)$ \\
\hline & Stunted & $600(25.2)$ & $612(24.9)$ \\
\hline & Thin & $482(20.2)$ & $450(18.3)$ \\
\hline \multicolumn{4}{|l|}{ Household characteristics $^{\text {b }}$} \\
\hline \multirow[t]{4}{*}{ Parental education } & No schooling & $726(29.4)$ & $925(34.7)$ \\
\hline & Primary schooling & $1,292(52.2)$ & $1,381(51.8)$ \\
\hline & Secondary schooling & $353(14.3)$ & $278(10.4)$ \\
\hline & Higher education & $102(4.1)$ & $83(3.1)$ \\
\hline \multirow[t]{5}{*}{ SES } & Poorest & $440(17.7)$ & $655(24.4)$ \\
\hline & Poor & $483(19.5)$ & $564(21.0)$ \\
\hline & Median & 465 (18.7) & $495(18.5)$ \\
\hline & Less poor & $524(21.1)$ & $509(19.0)$ \\
\hline & Least poor & $572(23.0)$ & $458(17.1)$ \\
\hline \multirow[t]{3}{*}{ Household size } & $1-5$ & $697(28.1)$ & $703(26.4)$ \\
\hline & $6-9$ & $1,444(58.3)$ & $1,580(59.3)$ \\
\hline & $10-31$ & 338 (13.6) & $382(14.3)$ \\
\hline Study endpoints-baseline $e^{e}$ & & 2,523 children & 2,710 children \\
\hline \multirow[t]{5}{*}{ Anaemia prevalence $^{f}(k=0.21)$} & Age-sex specific & $1,073(45.2)$ & $1,114(45.5)$ \\
\hline & Severe $(<70 \mathrm{~g} / \mathrm{l})$ & $14(0.6)$ & $14(0.6)$ \\
\hline & Moderate (70-89 g/l) & $43(1.8)$ & $55(2.2)$ \\
\hline & Mild (90-109 g/l) & $530(22.3)$ & $518(21.1)$ \\
\hline & None $(\geq 110 \mathrm{~g} / \mathrm{l})$ & $1,786(75.3)$ & $1,864(76.1)$ \\
\hline Haemoglobin (g/l) & Mean (SD) & $117.3(13.0)$ & $117.5(13.7)$ \\
\hline P. falciparum prevalence ${ }^{f, g}(k=1.03)$ & & - & $311(12.9)$ \\
\hline Class $1^{\mathrm{f}, \mathrm{h}}$ & & 1,222 children & 1,317 children \\
\hline Score: $0-20(I C C=0.07)$ & Sustained attention ${ }^{i}$ & $11.9(6.7)[0,20]$ & $12.1(6.6)[0,20]$ \\
\hline Score: $0-20(I C C=0.29)$ & Spelling & $8.6(4.5)[0,19]$ & $7.7(4.4)[0,20]$ \\
\hline Score: $0-30(I C C=0.11)$ & Arithmetic & $2.6(2.4)[0,17]$ & $2.6(2.5)[0,15]$ \\
\hline Class $5^{f, h}$ & & 1,301 children & 1,393 children \\
\hline Score: $0-20(I C C=0.23)$ & Sustained attention ${ }^{i}$ & $9.9(6.0)[0,20]$ & $10.4(5.7)[0,20]$ \\
\hline Score: $0-78(I C C=0.09)$ & Spelling & $27.9(11.8)[0,63]$ & $25.8(11.2)[1,59]$ \\
\hline
\end{tabular}


Table 1. Cont.

\begin{tabular}{|c|c|c|c|}
\hline Characteristics; $n(\%)^{a}$ & Measure/Subcharacteristic & Control & Intervention \\
\hline Score: $0-38($ ICC = 0.22) & Arithmetic & $29.4(5.6)[0,38]$ & $28.5(5.8)[0,38]$ \\
\hline \multicolumn{4}{|c|}{ 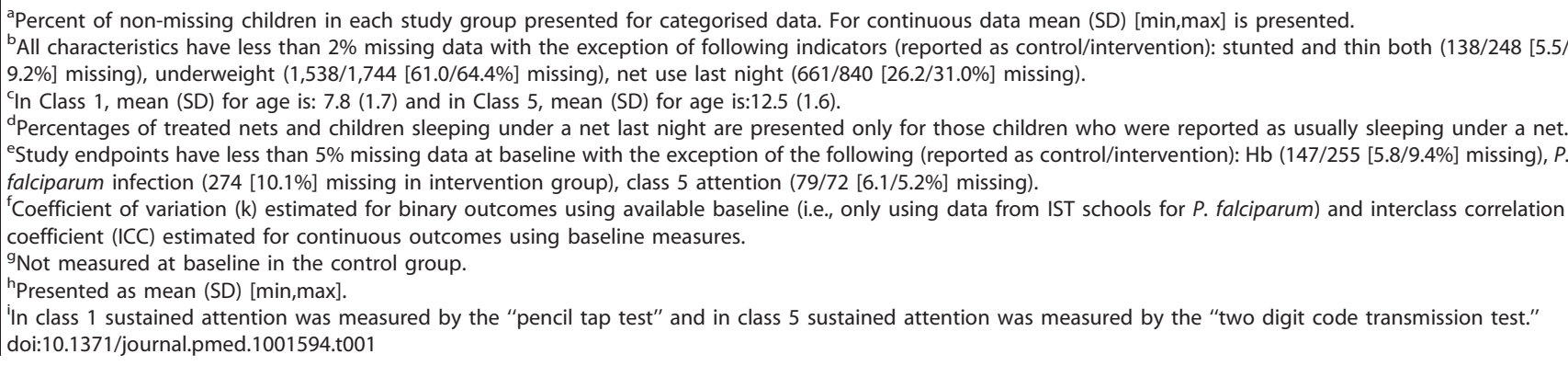 } \\
\hline
\end{tabular}

However, at 9-months follow-up, children in the younger class in the intervention group had lower mean adjusted scores for the spelling task and the same trend was observed at 24 months (Adj.MD: $-0.65,95 \%$ CI -1.11 to $-0.20, p=0.005)$. Similarly at 24 months, in the younger class, children in the intervention group scored on average 0.60 points lower in the arithmetic assessments than children in the control group (Adj.MD: $-0.60,95 \%$ CI: -1.02 to $-0.19, p=0.005$ ).

\section{Surveillance for Adverse Effects}

Active surveillance found that $4.5 \%(92 / 2,030)$ children reported one or more adverse effects within 2 days of receiving treatment, including headache $(68 ; 3.3 \%)$, stomach ache $(38$; $1.9 \%)$, dizziness $(17 ; 0.8 \%)$, vomiting $(7 ; 0.3 \%)$, and pruritis $(10$; $0.5 \%)$. During the 24 months of follow-up, 11 children died: five in the intervention group and six in the control group. Cause of death was investigated and included yellow fever, heart defect, leukaemia, drowning, trauma, pneumonia, and paediatric HIV. In the intervention group, none of these deaths occurred within 30 days of the screening and treatment and therefore were not attributed to the intervention.

\section{Discussion}

School-based malaria control is increasingly recognised as an important potential component for integrated school health packages [46]. However, as yet there is no consensus about the most effective malaria interventions for the alternative transmis- sion settings. To our knowledge, we conducted the first cluster randomised trial of the impact of school-based IST of malaria. We failed to detect any overall benefit of IST using AL on the health, attention, or educational achievement of school children in this low-moderate malaria transmission setting.

The reasonably high follow-up rates of, on average, $87.0 \%$ and $79.4 \%$ at the first and second follow-ups, respectively, equal between groups at each follow-up, suggest sample bias was not responsible for the lack of impact observed. The higher proportion of children unavailable for baseline health assessments was driven by a few initially apprehensive schools [47], which were subsequently assessed throughout the study and included in the unadjusted analyses. The differential baseline prevalence of $P$. falciparum in those children available and unavailable for follow-up in the intervention group may reflect a higher proportion of withdrawal and absenteeism on screening and assessment days in schools in low transmission regions, where there was no treatment benefit. However, such a situation is unlikely to have masked any impact of IST as historical exposure and current parasite prevalence is highly predictive of subsequent malaria risk [48,49], and as such these children were less likely to have been infected and thus gain any potential benefit from treatment over the study period.

The absence of apparent differences between study groups in relation to either Plasmodium infection or anaemia at 12 or 24 months is contradictory to predictions from simulation analyses of mass screening and treatment in a moderate transmission setting $[26,27]$. One reason for these contrasting results may be the

Table 2. Summary information for 2,710 study children in the IST intervention group by screening round.

\begin{tabular}{|c|c|c|c|c|c|c|c|}
\hline IST Round & Season & $\begin{array}{l}\text { Study } \\
\text { Children }^{a}\end{array}$ & $\begin{array}{l}n(\%) \\
\text { Screened }\end{array}$ & $\begin{array}{l}n(\%) \text { RDT } \\
\text { Positive }\end{array}$ & $\begin{array}{l}n(\%) \\
\text { Treated }\end{array}$ & $\begin{array}{l}n(\%) \text { Supervised } \\
\text { Treatment }^{\text {b }}\end{array}$ & $\begin{array}{l}\text { RDT } \\
\text { Sensitivity/Specificity }\end{array}$ \\
\hline Feb-Mar 2010 & Dry & $2,674(98.7)$ & $2,454(91.8)$ & 453 (18.5) & 449 (99.1) & $435(96.9)$ & $78.5 / 90.6$ \\
\hline Jun-Jul 2010 & Wet & 2,654 (97.9) & 2,430 (91.6) & 466 (19.2) & 465 (99.8) & $440(94.6)$ & $89.2 / 90.4$ \\
\hline Sept 2010 & Wet & 2,651 (97.8) & 2,368 (89.3) & 444 (18.8) & 443 (99.8) & $422(95.3)$ & $94.6 / 90.3$ \\
\hline Feb-Mar 2011 & Dry & 2,631 (97.1) & 2,291 (87.1) & $340(14.8)$ & 335 (98.5) & 306 (91.3) & $68.7 / 91.9$ \\
\hline Oct 2011 & Wet & $2,621(96.7)$ & $2,157(82.3)$ & $345(16.0)$ & $338(98.0)$ & 276 (81.7) & NA \\
\hline TOTALS & & 13,231 & $11,700(88.4)$ & $2,048(17.5)$ & $2,030(99.1)$ & 1,879 (92.6) & $82.7 / 90.8$ \\
\hline
\end{tabular}

Sensitivity and specificity of RDTs compared to expert microscopy is displayed.

${ }^{a}$ Study children are shown as a percentage of the 2,710 initially eligible for the intervention and loss at each stage represents withdrawals and/or deaths. Child transfer events are not included.

${ }^{\mathrm{b}}$ Children treated who were directly observed taking doses 1, 3, and 5 in school at the correct time and who reported taking the evening doses.

${ }^{\mathrm{c}}$ Microscopy results not available for visit 5 .

doi:10.1371/journal.pmed.1001594.t002 
Table 3. Effect of the IST intervention at 12- and 24-months follow-up on health outcomes anaemia and P. falciparum prevalence for study children.

\begin{tabular}{|c|c|c|c|c|c|c|c|}
\hline \multirow[t]{2}{*}{ Outcome } & \multicolumn{2}{|c|}{ Control (50 Schools) } & \multicolumn{2}{|c|}{$\begin{array}{l}\text { Intervention } \\
\text { (51 Schools) }\end{array}$} & \multirow[t]{2}{*}{$\begin{array}{l}\text { Risk Ratio } \\
(95 \% \mathrm{Cl})\end{array}$} & \multirow[t]{2}{*}{$p$-Value } & \multirow[t]{2}{*}{$\begin{array}{l}\text { Cluster-Size; } \\
\text { Range } \\
\text { (Average) }\end{array}$} \\
\hline & $N$ & $n(\%)^{b}$ & $N$ & $n(\%)^{b}$ & & & \\
\hline 12-MONTHS FOLLOW-UP & 2,478 & & 2,631 & & & & \\
\hline \multicolumn{8}{|l|}{ Prevalence of anaemia $^{c}$} \\
\hline Unadjusted & 2,146 & 837 (39.0\%) & 2,297 & 920 (40.1\%) & $1.03(0.91,1.16)$ & 0.646 & $15-55(44.0)$ \\
\hline Adjusted & 2,048 & $788(38.5 \%)$ & 2,142 & $858(40.1 \%)$ & $1.03(0.93,1.13)$ & 0.621 & $15-55(41.5)$ \\
\hline \multicolumn{8}{|l|}{ Prevalence of $P$. falciparum } \\
\hline Unadjusted & 2,106 & $302(14.3 \%)$ & 2,276 & $243(10.7 \%)$ & $0.76(0.49,1.18)$ & 0.221 & $11-55(43.4)$ \\
\hline Adjusted $^{d}$ & 2,106 & $302(14.3 \%)$ & 2,276 & $243(10.7 \%)$ & $0.71(0.46,1.11)$ & 0.131 & $11-55(43.4)$ \\
\hline 24-MONTHS FOLLOW-UP & 2,468 & & 2,619 & & & & \\
\hline \multicolumn{8}{|l|}{ Prevalence of anaemia $^{c}$} \\
\hline Unadjusted & 2,027 & 809 (39.9\%) & 2,173 & 910 (41.9\%) & $1.05(0.91,1.21)$ & 0.514 & $15-55(41.6)$ \\
\hline Adjusted & 1,935 & 765 (39.5\%) & 2,027 & $842(41.5 \%)$ & $1.00(0.90,1.11)$ & 0.953 & $14-55(39.5)$ \\
\hline \multicolumn{8}{|l|}{ Prevalence of $P$. falciparum } \\
\hline Unadjusted & 2,001 & $169(8.5 \%)$ & 2,139 & $253(11.8 \%)$ & $1.42(0.84,2.42)$ & 0.192 & $15-55(41.0)$ \\
\hline Adjusted $^{d}$ & 2,001 & $169(8.5 \%)$ & 2,139 & $253(11.8 \%)$ & $1.53(0.89,2.62)$ & 0.124 & $15-55(41.0)$ \\
\hline
\end{tabular}

Results presented (i) for all children with outcome data (unadjusted) and (ii) for those with baseline measurements of each outcome and accounting for age, sex, and stratification effects (adjusted) as the primary pre-specified analysis. $N$, number of children eligible for follow-up (not withdrawn or deceased).

Adjusted: for baseline age, sex, school mean exam score and literacy group (to account for stratification), and baseline measure of the outcome, where available; unadjusted: all children with outcome measures, not adjusted for any baseline or study design characteristics.

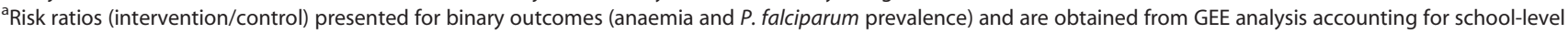
clustering.

${ }^{\mathrm{b}} \mathrm{Number}$ and percentage with outcome.

${ }^{c}$ Age-sex specific anaemia was defined using age and sex corrected WHO thresholds of $\mathrm{Hb}:<110 \mathrm{~g} / \mathrm{l}$ in children under 5 years; $<115 \mathrm{~g} / \mathrm{l}$ in children 5 to 11 years; $<120 \mathrm{~g} / \mathrm{l}$ in females 12 years and over and males 12 to 14.99 years old; and $<130 \mathrm{~g} / \mathrm{l}$ in males $\geq 15$ years. All female adolescents are assumed to not be pregnant. dNot including baseline $P$. falciparum infection.

doi:10.1371/journal.pmed.1001594.t003

different coverage rates, where the simulations assumed $80 \%$ intervention coverage of the whole community in contrast to this study where the IST intervention covered two classes of the school populations only. In this low-moderate transmission setting less than $20 \%$ of children screened were eligible for treatment at each round. However, the lack of differential impact on anaemia observed when schools were stratified by baseline prevalence of Plasmodium infection (a proxy for transmission intensity) and by number of treatments received at the individual level, suggests there was no impact on long-term health even amongst the children receiving AL treatment.

A possible explanation for the lack of impact of IST on anaemia at the group or individual level is high, localised, rates of reinfection and acquisition of new infections between screening rounds allowing no time for haematological recovery, indicated by the remarkably similar percentage of children RDT positive at each screening round. The use of AL may have contributed to rapid reinfection rates as it affords short (14-28 days) post-treatment protection [50,51]. Such a protection period would have provided extensive time at risk of acquiring new infections before the next round of IST at least three months later. A potential alternative would be dihydroartemisinin-piperaquine [52], which would afford a longer post-treatment prophylaxis period than AL between screening rounds and has recently been successfully evaluated as part of IPT in Uganda [53]. Additionally, increased frequency of screening, six times a year as opposed to three, could reduce the time at risk for parasite carriage and allow for haematological recovery, but would be logistically and financially prohibitive. The marked, but stable heterogeneity of Plasmodium infection observed over the two years (school-level prevalence range: $0 \%-75 \%$ ) resulted in several schools experiencing no infection throughout all screening rounds, and a small sample of schools exhibiting repeatedly high proportions of RDT positive study children at each round. This heterogeneity, compounded by the large proportion of untested and therefore untreated asymptomatic carriers remaining in the communities, likely led to study children in localised hotspots being exposed to high risk of infection immediately after treatment [20]. Analyses of the stability of infection at both the school and the individual level, and the environmental correlates of such patterns, will be presented in a future paper.

The evaluation identified two further limitations of the IST approach. First, there was variability in RDT performance between screening rounds, with lowest RDT sensitivity during the dry season. However, diagnostic performance in this analysis was estimated assuming microscopy as a "gold standard," and in light of concerns of the diagnostic accuracy of such reference tests, alternative methods of estimation for two or more malaria diagnostic tools in the absence of a "gold standard" have been suggested [54-56]. Additional analysis is underway to investigate diagnostic performance of RDTs and expert microscopy as well as the influence of individual, local transmission and seasonal factors during the two-year study period. The recent study conducted in Burkina Faso failed to show a significant reduction in parasitaemia in the dry season following community-wide screening and treatment campaigns in the previous dry season [29], suggesting that screening and treatment with RDTs is not sensitive enough to reduce transmission even when delivered in a mass campaign. The 
Table 4. Effect of the IST intervention at 9- and 24-months follow-up on sustained attention outcomes for younger (class 1 ) and older (class 5) children.

\begin{tabular}{|c|c|c|c|c|c|c|c|}
\hline \multirow[t]{2}{*}{ Outcome } & \multicolumn{2}{|c|}{$\begin{array}{l}\text { Control } \\
\text { (50 Schools) }\end{array}$} & \multicolumn{2}{|c|}{$\begin{array}{l}\text { Intervention } \\
\text { (51 Schools) }\end{array}$} & \multirow[t]{2}{*}{$\begin{array}{l}\text { Mean Difference }{ }^{a} \\
(95 \% \mathrm{CI})\end{array}$} & \multirow[t]{2}{*}{$p$-Value } & \multirow[t]{2}{*}{$\begin{array}{l}\text { Cluster-Size; } \\
\text { Range (Mean) }\end{array}$} \\
\hline & $N$ & $\begin{array}{l}\text { Mean } \\
(\mathrm{SD})^{\mathbf{b}}\end{array}$ & $N$ & $\begin{array}{l}\text { Mean } \\
(\mathrm{SD})^{\mathbf{b}}\end{array}$ & & & \\
\hline \multicolumn{8}{|l|}{ 9-MONTHS FOLLOW-UP } \\
\hline Class 1 (median age: 8 , range: 5-15) & 1210 & & 1,281 & & & & \\
\hline \multicolumn{8}{|l|}{ Sustained attention" (score: 0-20) } \\
\hline Unadjusted & 1,070 & $\begin{array}{l}8.48 \\
(3.63)\end{array}$ & 1,162 & $\begin{array}{l}8.43 \\
(3.76)\end{array}$ & $-0.04(-0.58$ to 0.51$)$ & 0.895 & $8-27(22.1)$ \\
\hline Adjusted & 1,030 & $\begin{array}{l}8.52 \\
(3.65)\end{array}$ & 1,144 & $\begin{array}{l}8.43 \\
(3.77)\end{array}$ & $-0.13(-0.66$ to 0.39$)$ & 0.623 & $5-27(21.7)$ \\
\hline Class 5 (median age: 12, range: $8-18$ ) & 1283 & & 1,365 & & & & \\
\hline \multicolumn{8}{|l|}{ Sustained attention $^{d}$ (score: 0-20) } \\
\hline Unadjusted & 1,180 & $\begin{array}{l}13.38 \\
(5.45)\end{array}$ & 1,231 & $\begin{array}{l}13.35 \\
(5.13)\end{array}$ & $-0.09(-0.77$ to 0.56$)$ & 0.799 & $8-30(23.9)$ \\
\hline Adjusted & 1,178 & $\begin{array}{l}13.38 \\
(5.45)\end{array}$ & 1,221 & $\begin{array}{l}13.40 \\
(5.10)\end{array}$ & $-0.21(-0.81$ to 0.39$)$ & 0.490 & $8-30(23.8)$ \\
\hline \multicolumn{8}{|l|}{ 24-MONTHS FOLLOW-UP } \\
\hline Class 1 (median age: 8, range: 5-15) & 1201 & & 1,269 & & & & \\
\hline \multicolumn{8}{|l|}{ Sustained attention ${ }^{c}$ (score: 0-20) } \\
\hline Unadjusted & 960 & $\begin{array}{l}13.45 \\
(5.15)\end{array}$ & 1,059 & $\begin{array}{l}13.20 \\
(4.96)\end{array}$ & $-0.26(-0.95$ to 0.43$)$ & 0.456 & $8-26(20.0)$ \\
\hline Adjusted & 923 & $\begin{array}{l}13.49 \\
(5.15)\end{array}$ & 1,041 & $\begin{array}{l}13.18 \\
(4.96)\end{array}$ & $-0.44(-1.09$ to 0.21$)$ & 0.180 & $4-25(19.6)$ \\
\hline Class 5 (median age: 12, range: 9-18) & 1267 & & 1,350 & & & & \\
\hline \multicolumn{8}{|l|}{ Sustained attention $^{d}$ (score: 0-20) } \\
\hline Unadjusted & 1,007 & $\begin{array}{l}14.22 \\
(4.90)\end{array}$ & 1,052 & $\begin{array}{l}14.66 \\
(4.60)\end{array}$ & $0.40(-0.14$ to 0.94$)$ & 0.144 & $6-31(20.4)$ \\
\hline Adjusted & 1,006 & $\begin{array}{l}14.21 \\
(4.90)\end{array}$ & 1,044 & $\begin{array}{l}14.70 \\
(4.58)\end{array}$ & $0.28(-0.23$ to 0.79$)$ & 0.283 & $6-29(20.3)$ \\
\hline
\end{tabular}

Results presented (i) for all children with outcome data (unadjusted) and (ii) for those with baseline measurements of each outcome and accounting for age, sex, and stratification effects (adjusted) as the primary pre-specified analysis. $N$, number of children eligible for follow-up (not withdrawn or deceased).

Adjusted: for baseline age, sex, school mean exam score and literacy group (to account for stratification), and baseline measure of the outcome, where available;

unadjusted: all children with outcome measures, not adjusted for any baseline or study design characteristics.

${ }^{\mathrm{a}}$ Mean difference (intervention-control) are obtained from GEE analysis accounting for school-level clustering.

${ }^{\mathrm{b}}$ Mean score and SD at follow-up.

'Pencil tap test was conducted at baseline and single digit code transmission task was conducted at 9- and 24-months follow-ups.

${ }^{\mathrm{d} D o u b l e ~ d i g i t ~ c o d e ~ t r a n s m i s s i o n ~ w a s ~ c o n d u c t e d ~ a t ~ b a s e l i n e ~ a n d ~ b o t h ~ f o l l o w-u p s . ~}$

doi:10.1371/journal.pmed.1001594.t004

use of PCR would constitute a more sensitive tool, additionally detecting subpatent infections that contribute to transmission [57-59], but would be operationally challenging. Second, there was a decline in supervised treatment over time, as it became logistically difficult for children who were absent on screening day and subsequently treated on a repeat visit to be followed up on treatment day two and three by the nurse. Such children and/or their guardians and older siblings were given the full regimen with instructions on how to take the doses at home over the three days [60]. Altering the treatment supervision by the nurse from three days to the first day only would greatly reduce the cost of the IST intervention [61]. Although evidence indicates that unsupervised treatment is as effective at clearing parasitaemia as fully supervised treatment in clinical cases [62], unsupervised compliance may be lower when treating asymptomatic infection. Low efficacy of AL in the study is possible. No specific treatment efficacy evaluation was performed during this trial; however, although there is mixed evidence as to whether there is a slight decline in efficacy of AL in
Kenya [63,64], overall treatment success is thought to remain reasonably high.

In a region such as coastal Kenya, where food security is particularly low $[65,66]$ and malaria transmission is low-moderate, it is probable that factors such as long term nutritional status, short term access to food, and helminth infections are stronger contributors to the aetiology of anaemia in this setting [67] than parasitaemia. These factors would result in a limited impact on anaemia though a programme targeting malaria only, rather than a package containing a combination of school-feeding, deworming, and malaria control. This study thus contrasts with the previous IPT study conducted in Nyanza province, Kenya [24], where malaria is predicted to be the greatest contributor to anaemia [67], enabling a malaria control programme to have a large impact on anaemia directly.

Our finding of no significant differences between groups for sustained attention in either the younger or older classes at either follow-up is consistent with expectations, based on the lack of effect of IST on the assumed mediator, health. Likewise with the 
Table 5. Effect of the IST intervention at 9- and 24-months follow-up on educational achievement (spelling and arithmetic) outcomes for younger (class 1) and older (class 5) children.

\begin{tabular}{|c|c|c|c|c|c|c|c|}
\hline \multirow{2}{*}{ Outcome; $N(\%)$} & \multicolumn{2}{|c|}{ Control (50 Schools) } & \multicolumn{2}{|c|}{$\begin{array}{l}\text { Intervention (51 } \\
\text { Schools) }\end{array}$} & \multirow[t]{2}{*}{$\begin{array}{l}\text { Mean Difference }{ }^{a} \\
(95 \% \mathrm{Cl})\end{array}$} & \multirow{2}{*}{$p$-Value } & \multirow[t]{2}{*}{$\begin{array}{l}\text { Cluster-Size; } \\
\text { Range (Mean }\end{array}$} \\
\hline & $N$ & Mean (SD) $)^{b}$ & $N$ & Mean $(S D)^{b}$ & & & \\
\hline \multicolumn{8}{|l|}{ 9-MONTHS FOLLOW-UP } \\
\hline Class 1 (median age: 8, range: $5-15$ ) & 1,210 & & 1,281 & & & & \\
\hline \multicolumn{8}{|l|}{ Spelling (score: $0-20)^{c}$} \\
\hline Unadjusted & 1,068 & $11.70(4.59)$ & 1,162 & $10.47(4.57)$ & $-1.23(-2.21$ to -0.24$)$ & 0.015 & $8-27(22.1)$ \\
\hline Adjusted & 1,060 & $11.69(4.59)$ & 1,133 & $10.49(4.58)$ & $-0.67(-1.26$ to -0.08$)$ & 0.026 & $8-27(21.7)$ \\
\hline \multicolumn{8}{|l|}{ Arithmetic (score: $0-20)^{d}$} \\
\hline Unadjusted & 1,071 & $4.21(3.13)$ & 1,162 & $4.04(3.26)$ & $-0.17(-0.60$ to 0.26$)$ & 0.433 & $8-27(22.1)$ \\
\hline Adjusted & 1,069 & $4.21(3.12)$ & 1,143 & $4.07(3.28)$ & $-0.21(-0.54$ to 0.12$)$ & 0.214 & $8-27(21.9)$ \\
\hline Class 5 (median age: 12, range: $8-18$ ) & 1,283 & & 1,365 & & & & \\
\hline \multicolumn{8}{|l|}{ Spelling (score: $0-75)^{e}$} \\
\hline Unadjusted & 1,169 & $31.34(12.61)$ & 1,223 & $28.73(12.36)$ & $-2.73(-5.26$ to -0.19$)$ & 0.035 & $8-30(23.7)$ \\
\hline Adjusted & 1,154 & $31.37(12.60)$ & 1,214 & $28.76(12.34)$ & $-0.31(-1.26$ to 0.63$)$ & 0.515 & 8-30 (23.4) \\
\hline \multicolumn{8}{|l|}{ Arithmetic (score: $0-30)^{f}$} \\
\hline Unadjusted & 1,180 & $31.15(5.49)$ & 1,229 & $30.72(5.17)$ & $-0.49(-1.40$ to 0.42$)$ & 0.294 & 8-30 (23.9) \\
\hline Adjusted & 1,173 & $31.14(5.50)$ & 1,210 & $30.73(5.17)$ & $0.13(-0.41$ to 0.68$)$ & 0.629 & $8-30(23.6)$ \\
\hline \multicolumn{8}{|l|}{ 24-MONTHS FOLLOW-UP } \\
\hline Class 1 (median age: 8, range: 5-15) & 1,201 & & 1,269 & & & & \\
\hline \multicolumn{8}{|l|}{ Spelling (score: $0-20)^{c}$} \\
\hline Unadjusted & 961 & $12.03(3.05)$ & 1,062 & $11.04(3.49)$ & $-0.97(-1.54$ to -0.40$)$ & 0.001 & $8-26(20.0)$ \\
\hline Adjusted & 954 & $12.02(3.05)$ & 1,036 & $11.04(3.50)$ & $-0.65(-1.11$ to -0.20$)$ & 0.005 & $8-25(19.7)$ \\
\hline \multicolumn{8}{|l|}{ Arithmetic (score: $0-30)^{g}$} \\
\hline Unadjusted & 962 & $5.97(3.05)$ & 1,061 & $5.38(2.97)$ & $-0.59(-1.08$ to -0.10$)$ & 0.018 & $8-26(20.0)$ \\
\hline Adjusted & 960 & $5.97(3.04)$ & 1,042 & $5.40(2.97)$ & $-0.60(-1.02$ to -0.19$)$ & 0.005 & 8-25 (19.9) \\
\hline Class 5 (median age: 12, range: $9-18$ ) & 1,267 & & 1,350 & & & & \\
\hline \multicolumn{8}{|l|}{ Spelling (score: $0-78)^{e}$} \\
\hline Unadjusted & 1,010 & $35.28(12.91)$ & 1,060 & $33.97(12.79)$ & $-1.58(-4.01$ to 0.85$)$ & 0.202 & 6-31 (20.5) \\
\hline Adjusted & 996 & $35.33(12.85)$ & 1,052 & $34.04(12.75)$ & $0.71(-0.34$ to 1.76$)$ & 0.183 & $6-29(20.3)$ \\
\hline \multicolumn{8}{|l|}{ Arithmetic (score: $0-30)^{f}$} \\
\hline Unadjusted & 1,016 & $21.20(5.47)$ & 1,062 & $20.15(5.68)$ & $-1.07(-2.15$ to 0.00$)$ & 0.050 & 6-31 (20.6) \\
\hline Adjusted & 1,009 & $21.20(5.48)$ & 1,045 & $20.18(5.69)$ & $-0.49(-1.32$ to 0.34$)$ & 0.243 & $6-29(20.3)$ \\
\hline
\end{tabular}

Results presented (i) for all children with outcome data (unadjusted) and (ii) for those with baseline measurements of each outcome and accounting for age, sex, and stratification effects (adjusted) as the primary pre-specified analysis. N, number of children eligible for follow-up (not withdrawn or deceased).

Adjusted: for baseline age, sex, school mean exam score and literacy group (to account for stratification) and baseline measure of the outcome, where available; unadjusted: all children with outcome measures, not adjusted for any baseline or study design characteristics.

a Mean difference (intervention-control) for scores on spelling and arithmetic are obtained from GEE analysis accounting for school-level clustering.

${ }^{\mathrm{b}}$ Mean score and SD at follow-up.

'The same class 1 spelling task was given at baseline, 9- and 24-months follow-ups, with different words used for the 24-month follow-up.

dSame addition task conducted at 9-months follow-up and at baseline, hence baseline adjustment is for the same task.

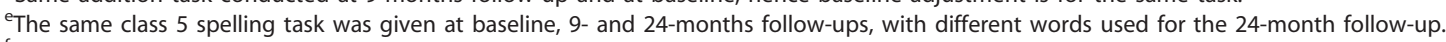

'Same arithmetic task conducted at baseline, 9- and 24-months follow-ups, with different sums used for the 24-month follow-up.

${ }^{9}$ Addition task conducted at baseline and arithmetic task containing addition, subtraction, multiplication, and division conducted at 24-months follow-up, hence baseline adjustment for different task.

doi:10.1371/journal.pmed.1001594.t005

adjusted literacy and numeracy scores in the older class at both follow-ups, no significant differences between groups were found. However, in the younger class at both 9 and 24 months, there was an apparent negative effect of the IST intervention on literacy scores and on arithmetic scores at 24 months. This seemingly negative impact of IST was found only in the younger class, where the literacy intervention was implemented. As no statistical interaction between the two interventions was detected in the younger class, the differences between study groups cannot be attributed to an effect of the literacy intervention. Because of the multiple tests conducted, this finding could be due to chance. If we were to use a highly conservative Bonferroni correction for the 16 tests (two health and six education outcomes, all at two follow-ups) from adjusted models, the apparent negative effects on spelling and arithmetic would lie close to the updated significance level. Alternatively, these findings could demonstrate a negative effect of the by-term screening, involving an uncomfortable finger prick [68], with the intervention group experiencing increased 
apprehension of the finger prick during the education assessments as they associated the presence of our research team with the IST process [47], or reduced classroom attendance throughout the year in this group to avoid the IST intervention, or a combination. However, attendance measured at health and education assessment visits indicated no significant differences in attendance between the groups. Findings of negative educational or cognitive effects of health interventions are rare but not unprecedented [69] and suggest the need for experimental evaluations to test assumptions about the educational benefits of health programs. The finding of low overall achievement levels and minimal learning is consistent with the international literature and findings from Kenya [36]. The causes are well documented and include a lack of a culture of literacy, lack of effective teaching methods, poorly resourced teachers with large classes, poor health of children, and competition for children's time at home [70,71].

Our study has a number of limitations. First, given the nature of the intervention, it was not possible to blind the parents, participants, or field officers delivering the IST intervention to experimental assignment, which could have led to a possible "John Henry" effect whereby children in the control group adjust their behaviour as they know they are not receiving the intervention, for example in risk aversion and treatment seeking behaviour. Biomedical and educational assessors were blinded where feasible. Second, study children's access to alternative malaria treatments outside of the school-based IST rounds was not monitored during the two years of the trial. However, due to the randomised design of the trial and the fact that the majority of infections in this age group and population were asymptomatic at assessment and screening points, we have no reason to suspect that study children's access to treatment outside of this trial differed greatly across study groups. Finally, the lack of multiple testing adjustments may have increased the possibility of type 1 error, and results should be interpreted in light of this possible error, but it is unlikely to have masked a beneficial effect of IST.

\section{Conclusion}

In summary, our findings show there are no health or education benefits of implementing school-based IST with AL in a low to moderate transmission setting such as this study site, as a high proportion of children screened do not require treatment and those who do largely live in focal high transmission regions, where rapid re-infection occurs between screening rounds and results in no lasting gains from treatment. Nevertheless, our results do highlight a potential role for schools as screening platforms. School screenings using RDTs could provide an operationally efficient method to initially identify transmission hotspots for targeted community control [72]. School surveys have proved a useful platform for defining heterogeneities in Plasmodium transmission over large geographical areas in a more rapid and low cost manner than community surveys $[73,74]$. The results from this study's screening rounds present a case for the use of schools in also depicting local transmission heterogeneities, which can be extrapolated to the local community [75] and aid in developing targeted community-wide comprehensive interventions, such as localised indoor residual screening and larviciding, with biennial school screenings used to monitor the success of these interventions. The use of schools in this way is a focus of our current research.

\section{Supporting Information}

Alternative Language Abstract S1 Spanish translation of the abstract by Jorge Cano Ortega.

(DOC)
Alternative Language Abstract S2 Swahili translation of the abstract by Carlos Mcharo and George Okello. (DOG)

Alternative Language Abstract S3 French translation of the abstract by Birgit Nikolay and Fiona Majorin.

(DOC)

\section{Ghecklist S1 GONSORT checklist.}

(DOC)

\section{Protocol S1 Study protocol.}

(PDF)

Table S1 Baseline measures for 5,233 study children with missing 12-months follow-up health data versus those not missing 12-months follow-up health data across both the control and IST intervention groups. (DOC)

Table S2 Baseline measures for 5,233 study children with missing 24-months follow-up health data versus those not missing 24-months follow-up health data across both the control and IST intervention groups. (DOC)

Table S3 Results from missing data analysis for anaemia. Effect of the IST intervention at 12- and 24-months follow-up on the primary health outcome of anaemia for study children combined using a longitudinal, random effects regression modeling approach. Results presented (i) for all children with either 12- or 24-months follow-up measurements of the outcome (unadjusted), (ii) for those with baseline measurements of the outcome and accounting for age, sex, and stratification effects as the primary pre-specified analysis, and (iii) for those additionally with baseline measures of parental education, SES, and baseline educational level (measured by baseline spelling) as further predictors of missingness. (DOC)

Table S4 Baseline measures for study children with missing 9-months follow-up education data versus those not missing 9-months follow-up education data across both the control and intervention groups. (DOC)

Table S5 Baseline measures for study children with missing 24-months follow-up education data versus those not missing 24-months follow-up education data across both the control and intervention groups. (DOC)

Table S6 Results from missing data analysis for sustained attention. Effect of the IST intervention at 9- and 24-months follow-up on sustained attention outcomes for younger (class 1) and older (class 5) children combined using a longitudinal, random effects regression modeling approach. Results presented (i) for all children with either 9- or 24-months follow-up measurements of the outcome (unadjusted), (ii) for those with baseline measurements of the outcome and accounting for age, sex, and stratification effects as the primary pre-specified analysis, and (iii) for those additionally with baseline measures of parental education, SES, and baseline educational level (measured by baseline spelling) as further predictors of missingness.

(DOC)

Table S7 Results from missing data analysis for spelling. Effect of the IST intervention at 9- and 24-months follow-up on spelling outcomes for younger (class 1) and older (class 5) children combined using a longitudinal, random effects regression modeling approach. Results presented (i) for all children with either 9- or 24- 
months follow-up measurements of the outcome (unadjusted), (ii) for those with baseline measurements of the outcome and accounting for age, sex, and stratification effects as the primary pre-specified analysis, and (iii) for those additionally with baseline measures of parental education, SES, and baseline educational level (measured by baseline spelling) as further predictors of missingness.

(DOC)

Table S8 Sensitivity analyses considering transfers across the study period. Effect of the IST intervention at 12- and 24-months follow-up on health outcomes for study children. Results presented (i) for all children with either 12- or 24months follow-up measurements of the outcome (unadjusted) with children who transferred schools excluded and (ii) for those with baseline measurements of each outcome and accounting for age, sex, and stratification effects as the primary pre-specified analysis with children who transferred schools excluded.

(DOG)

Table S9 Analysis stratified by categories of $P$. falciparum prevalence at baseline. Effect of the IST intervention at 12- and 24-months follow-up on the prevalence of anaemia, by baseline prevalence category of $P$. falciparum (control school prevalence estimated using 12-month follow-up data) with adjustment for age, sex, and stratification effects.

(DOG)

Table S10 Analysis stratified by number of AL treatments received. Effect of the IST intervention at 12- and 24-months follow-up within the IST intervention group by number of positive results and subsequent treatments received at the individual level.

(DOG)

\section{References}

1. O'Meara WP, Mangeni JN, Steketee R, Greenwood B (2010) Changes in the burden of malaria in sub-Saharan Africa. Lancet Infect Dis 10: 545-555.

2. Ceesay SJ, Casals-Pascual C, Nwakanma DC, Walther M, Gomez-Escobar N, et al. (2010) Continued decline of malaria in The Gambia with implications for elimination. PLoS ONE 5: e12242. doi:10.1371/journal.pone.0012242

3. Kalayjian BC, Malhotra I, Mungai PL, Holding PA, King CH (2013) Marked decline in malaria prevalence among pregnant women and their offspring from 1996 to 2010 on the South Kenyan coast. Am J Trop Med Hyg 89: 1129 1134 .

4. Ceesay SJ, Casals-Pascual C, Erskine J, Anya SE, Duah NO, et al. (2008) Changes in malaria indices between 1999 and 2007 in The Gambia: a retrospective analysis. Lancet 372: 1545-1554.

5. O’Meara WP, Bejon P, Mwangi TW, Okiro EA, Peshu N, et al. (2008) Effect of a fall in malaria transmission on morbidity and mortality in Kilifi, Kenya. Lancet 372: $1555-1562$

6. Greenwood BM (2008) Control to elimination: implications for malaria research. Trends Parasitol 24: 449-454.

7. Smith DL, Guerra CA, Snow RW, Hay SI (2007) Standardizing estimates of the Plasmodium falciparum parasite rate. Malar J 6: 131

8. Brooker S, Kolaczinski JH, Gitonga CW, Noor AM, Snow RW (2009) The use of schools for malaria surveillance and programme evaluation in Africa. Malar J 8: 231.

9. Brooker S, Guyatt H, Omumbo J, Shretta R, Drake L, et al. (2000) Situation analysis of malaria in school-aged children in Kenya - what can be done? Parasitol Today 16: 183-186.

10. Japan International Cooperation Agency (JICA) (2012) Basic education sector analysis report: Kenya. Tokyo: JICA.

11. Kurtzhals JA, Addae MM, Akanmori BD, Dunyo S, Koram KA, et al. (1999) Anaemia caused by asymptomatic Plasmodium falciparum infection in semiimmune African schoolchildren. Trans R Soc Trop Med Hyg 93: 623-627.

12. Menendez C, Fleming AF, Alonso PL (2000) Malaria-related anaemia. Parasitol Today 16: 469-476.

13. Fernando D, Wickremasinghe R, Mendis KN, Wickremasinghe AR (2003) Cognitive performance at school entry of children living in malaria-endemic areas of Sri Lanka. Trans R Soc Trop Med Hyg 97: 161-165.

14. Kihara M, Garter JA, Newton CRJC (2006) The effect of Plasmodium falciparum on cognition: a systematic review. Trop Med Int Health 11: 386-397.

15. Fernando SD, Rodrigo C, Rajapakse S (2010) The 'hidden' burden of malaria: cognitive impairment following infection. Malar J 9: 366.

16. Nankabirwa J, Wandera B, Kiwanuka N, Staedke SG, Kamya MR, et al. (2013) Asymptomatic Plasmodium infection and cognition among primary schoolchil-
Text S1 Methods for the missing data models. (DOC)

\section{Acknowledgments}

We are grateful to all the teachers, children, and parents who participated in this trial and to all the members of the survey teams for their tireless effort and excellent work. We acknowledge the support provided by the ministries of education and health at national and district levels, and thank Elizabeth Juma, Charles Mwandawiro, Kelvin Kinyua, Bob Ogada, Veronica Wambugu, Siân Clarke, Tansy Edwards, Caroline Hagelskamp, Sharon Wolf, Geetha Mathews, Chandana Jasti, and Elizabeth Adelman for their contributions and support. Thanks go to Abdunoor Mulokozi for advice on surveillance of adverse events and to Teun Bousema and David Schellenberg for their comments on a draft manuscript. We would also like to extend our sincere thanks to the members of the World Bank's Development Impact Evaluation Initiative (Arianna Legovini, Jed Friedman, Marcus Holmlund, and Edit Velényi), the study advisory group (David Schellenberg, Greg Fegan, Don Bundy, and Diana Elbourne), and the data monitoring committee (Feiko ter Kuile, Penelope PhillipsHoward, and Carole Torgerson).

\section{Author Contributions}

Conceived and designed the experiments: SJB MCHJ KN. Performed the experiments: KEH GO CM JK MMD. Analyzed the data: ELT EA KEH SJB ELT. Contributed reagents/materials/analysis tools: KN. Wrote the first draft of the manuscript: KEH SJB ELT. Contributed to the writing of the manuscript: GO MCHJ. ICMJE criteria for authorship read and met: KEH GO ELT KN CM JK EA MMD MCHJ SJB. Agree with manuscript results and conclusions: KEH GO ELT KN CM JK EA MMD MCHJ SJB. Enrolled patients: KEH GO CM JK.

dren in a high malaria transmission setting in Uganda. Am J Trop Med Hyg 88: $1102-1108$

17. Al Serouri AW, Grantham-McGregor SM, Greenwood B, Costello A (2000) Impact of asymptomatic malaria parasitaemia on cognitive function and school achievement of schoolchildren in the Yemen Republic. Parasitology 121: 337-345.

18. Fernando D, de Silva D, Carter R, Mendis KN, Wickremasinghe R (2006) A randomized, double-blind, placebo-controlled, clinical trial of the impact of malaria prevention on the educational attainment of school children. Am J Trop Med Hyg 74: 386-393.

19. Moonen B, Cohen JM, Snow RW, Slutsker L, Drakeley C, et al. (2010) Operational strategies to achieve and maintain malaria elimination. Lancet 376 : 1592-1603.

20. Bousema T, Griffin JT, Sauerwein RW, Smith DL, Churcher TS, et al. (2012) Hitting hotspots: spatial targeting of malaria for control and elimination. PLoS Med 9: e1001165. doi:10.1371/journal.pmed.1001165

21. Githeko AK, Brandling-Bennett AD, Beier M, Atieli F, Owaga M, et al. (1992) The reservoir of Plasmodium falciparum malaria in a holoendemic area of western Kenya. Trans R Soc Trop Med Hyg 86: 355-358.

22. Bousema JT, Gouagna LC, Drakeley CJ, Meutstege AM, Okech BA, et al (2004) Plasmodium falciparum gametocyte carriage in asymptomatic children in western Kenya. Malar J 3: 18.

23. Brooker S (2009) Malaria control in schools: a toolkit on effective education sector responses to malaria in Africa. Washington (D.C.): The World Bank

24. Clarke SE, Jukes MCH, Njagi JK, Khasakhala L, Cundill B, et al. (2008) Effect of intermittent preventive treatment of malaria on health and education in schoolchildren: a cluster-randomised, double-blind, placebo-controlled trial, Lancet 372: 127-138.

25. Barger B, Maiga H, Traore OB, Tekete M, Tembine I, et al. (2009) Intermittent preventive treatment using artemisinin-based combination therapy reduces malaria morbidity among school-aged children in Mali. Trop Med Int Health 14: $784-791$.

26. Griffin JT, Hollingsworth TD, Okell LC, Churcher TS, White M, et al. (2010) Reducing Plasmodium falciparum malaria transmission in Africa: a model-based evaluation of intervention strategies. PLoS Med 7: e1000324. doi:10.1371/ journal.pmed.1000324.

27. Kern SE, Tiono AB, Makanga M, Gbadoe AD, Premji Z, et al. (2011) Community screening and treatment of asymptomatic carriers of Plasmodium falciparum with artemether-lumefantrine to reduce malaria disease burden: a modelling and simulation analysis. Malar J 10: 210.

28. Tagbor H, Bruce J, Agbo M, Greenwood B, Chandramohan D (2010) Intermittent screening and treatment versus intermittent preventive treatment of 
malaria in pregnancy: a randomised controlled non-inferiority trial. PLoS ONE 5: e14425. doi:10.1371/journal.pone.0014425

29. Tiono AB, Ouedraogo A, Ogutu B, Diarra A, Coulibaly S, et al. (2013) A controlled, parallel, cluster-randomized trial of community-wide screening and treatment of asymptomatic carriers of Plasmodium falciparum in Burkina Faso. Malar J 12: 79.

30. Brooker S, Okello G, Njagi K, Dubeck MM, Halliday KE, et al. (2010) Improving educational achievement and anaemia of school children: design of a cluster randomised trial of school-based malaria prevention and enhanced literacy instruction in Kenya. Trials 11: 93.

31. Snow RW, Schellenberg JR, Peshu N, Forster D, Newton CR, et al. (1993) Periodicity and space-time clustering of severe childhood malaria on the coast of Kenya. Trans R Soc Trop Med Hyg 87: 386-390.

32. Mbogo CM, Mwangangi JM, Nzovu J, Gu W, Yan G, et al. (2003) Spatial and temporal heterogeneity of Anopheles mosquitoes and Plasmodium falciparum transmission along the Kenyan coast. Am J Trop Med Hyg 68: 734-742.

33. Mwangangi JM, Mbogo CM, Orindi BO, Muturi EJ, Midega JT, et al. (2013) Shifts in malaria vector species composition and transmission dynamics along the Kenyan coast over the past 20 years. Malar J 12: 13.

34. Bustinduy AL, Thomas CL, Fiutem JJ, Parraga IM, Mungai PL, et al. (2011) Measuring fitness of Kenyan children with polyparasitic infections using the 20meter shuttle run test as a morbidity metric. PLoS Negl Trop Dis 5: e1213. doi: 10.1371 /journal.pntd.0001213

35. Halliday KE, Karanja P, Turner EL, Okello G, Njagi K, et al. (2012) Plasmodium falciparum, anaemia and cognitive and educational performance among school children in an area of moderate malaria transmission: baseline results of a cluster randomized trial on the coast of Kenya. Trop Med Int Health 17: 532-549.

36. Dubeck MM, Jukes MCH, Okello G (2012) Early primary literacy instruction in Kenya. Comparative Education Review 56: 48-68.

37. Martinez EZ, Louzada-Neto F, Derchain SFM, Achcar JA, Gontijo RC, et al. (2008) Bayesian estimation of performance measures of cervical cancer screening tests in the presence of covariates and absence of a gold standard. Cancer Inform 6: $33-46$.

38. Division of Malaria Control Ministry of Public Health and Sanitation (2009) National Malaria Strategy 2009-2017. Nairobi: Kenya NMCP.

39. Manly T, Robertson IH, Anderson V, Nimmo-Smith I (1999) Test of everyday attention for children: TEA-Ch. Bury St Edmunds, UK: Thames Valley Test Company.

40. Luria AR (1966) Higher cortical functions in man. New York: Basic Books.

41. Invernizzi M, Sullivan A, Meier J, Swank L (2004) PALS: phonological awareness literacy screening. Charlottesville (Virginia): University of Virginia.

42. Benoist B, McLean E, Egli I, Cogswell M (2008) Worldwide prevalence of anaemia 1993-2003: WHO global database on anaemia. Geneva: WHO.

43. Filmer D, Pritchett LH (2001) Estimating wealth effects without expenditure data-or tears: an application to educational enrollments in states of India. Demography 38: 115-132.

44. WHO (2007) Anthroplus: growth reference 5-19 years. WHO, editor. Geneva: WHO.

45. Hayes RJ, Moulton LH (2009) Cluster randomised trials. Hall G, editor. London: CRC Press.

46. Bundy D (2011) Rethinking school health: a key component of education for all. Washington (D.C.): World Bank.

47. Okello G, Jones C, Bonareri M, Ndegwa SN, McHaro C, et al. (2013) Challenges for consent and community engagement in the conduct of cluster randomized trial among school children in low income settings: experiences from Kenya. Trials 14: 142.

48. Bejon P, Warimwe G, Mackintosh CL, Mackinnon MJ, Kinyanjui SM, et al. (2009) Analysis of immunity to febrile malaria in children that distinguishes immunity from lack of exposure. Infect Immun 77: 1917-1923.

49. Bousema T, Kreuels B, Gosling R (2011) Adjusting for heterogeneity of malaria transmission in longitudinal studies. J Infect Dis 204: 1-3.

50. Sowunmi A, Gbotosho GO, Happi CT, Adedeji AA, Fehintola FA, et al. (2007) Therapeutic efficacy and effects of artemether-lumefantrine and amodiaquinesulfalene-pyrimethamine on gametocyte carriage in children with uncomplicated Plasmodium falciparum malaria in southwestern Nigeria. Am J Trop Med Hyg 77: 235-241.

51. Woodring JV, Ogutu B, Schnabel D, Waitumbi JN, Olsen CH, et al. (2010) Evaluation of recurrent parasitemia after artemether-lumefantrine treatment for uncomplicated malaria in children in western Kenya. Am J Trop Med Hyg 83: 458-464.

52. Nambozi M, Van Geertruyden J-P, Hachizovu S, Chaponda M, Mukwamataba D, et al. (2011) Safety and efficacy of dihydroartemisinin-piperaquine versus artemether-lumefantrine in the treatment of uncomplicated Plasmodium falciparum malaria in Zambian children. Malar J 10: 50.

53. Nankabirwa J, Cundill B, Clarke S, Kabatereine N, Rosenthal PJ, et al. (2010) Efficacy, safety, and tolerability of three regimens for prevention of malaria: a randomized, placebo-controlled trial in Ugandan schoolchildren. PLoS ONE 5: e13438. doi:10.1371/journal.pone.0013438

54. Ochola LB, Vounatsou P, Smith T, Mabaso MLH, Newton CRJC (2006) The reliability of diagnostic techniques in the diagnosis and management of malaria in the absence of a gold standard. Lancet Infect Dis 6: 582-588.

55. Speybroeck N, Praet N, Claes F, Van Hong N, Torres K, et al. (2011) True versus apparent malaria infection prevalence: the contribution of a Bayesian approach. PLoS ONE 6: e16705. doi:10.1371/journal.pone.0016705

56. Gonçalves L, Subtil A, de Oliveira MR, do Rosário V, Lee P-W, et al. (2012) Bayesian latent class models in malaria diagnosis. PLoS ONE 7: e40633. doi: 10.1371 /journal.pone. 0040633

57. Okell LC, Ghani AC, Lyons E, Drakeley CJ (2009) Submicroscopic infection in Plasmodium falciparum-endemic populations: a systematic review and metaanalysis. J Infect Dis 200: 1509-1517.

58. Okell LC, Bousema T, Griffin JT, Ouédraogo AL, Ghani AC, et al. (2012) Factors determining the occurrence of submicroscopic malaria infections and their relevance for control. Nat Commun 3: 1237.

59. Dinko B, Oguike MC, Larbi JA, Bousema JT, Sutherland CJ (2013) Persistent detection of Plasmodium falciparum, P. malariae, P. ovale curtisi and P. ovale wallikeri after ACT treatment of asymptomatic Ghanaian school-children. Int J Parasitol 3: 45-50.

60. Okello G, Ndegwa SN, Halliday KE, Hanson K, Brooker SJ, et al. (2012) Local perceptions of intermittent screening and treatment for malaria in school children on the south coast of Kenya. Malar J 11: 185.

61. Drake TL, Okello G, Njagi K, Halliday KE, Jukes MC, et al. (2011) Cost analysis of school-based intermittent screening and treatment of malaria in Kenya. Malar J 10: 273.

62. Piola P, Fogg C, Bajunirwe F, Biraro S, Grandesso F, et al. (2005) Supervised versus unsupervised intake of six-dose artemether-lumefantrine for treatment of acute, uncomplicated Plasmodium falciparum malaria in Mbarara, Uganda: a randomised trial. Lancet 365: 1467-1473.

63. Borrmann S, Sasi P, Mwai L, Bashraheil M, Abdallah A, et al. (2011) Declining responsiveness of Plasmodium falciparum infections to artemisinin-based combination treatments on the Kenyan coast. PLoS ONE 6: e26005. doi:10.1371/ journal.pone.0026005

64. Agarwal A, McMorrow M, Onyango P, Otieno K, Odero C, et al. (2013) A randomized trial of artemether-lumefantrine and dihydroartemisinin-piperaquine in the treatment of uncomplicated malaria among children in western Kenya. Malar J 12: 254.

65. National Coordination Agency for Population and Development (2005) Kwale District Strategic Plan 2005-2010 for implementation of the National Population Poilcy for Sustainable Development. Nairobi: National Coordination Agency for Population and Development. 1-55 p.

66. Kenya Food Security Steering Group (2012) The 2011/12 Short Rains Season Assessment Report. Nairobi: Kenya Food Security Steering Group. 1-42 p.

67. Pullan RL, Gitonga G, Mwandawiro C, Snow RW, Brooker SJ (2013) Estimating the relative contribution of parasitic infections and nutrition for anaemia among school-aged children in Kenya: a subnational geostatistical analysis. BMJ Open 3.

68. Smith LA, Jones C, Adjei RO, Antwi GD, Afrah NA, et al. (2010) Intermittent screening and treatment versus intermittent preventive treatment of malaria in pregnancy: user acceptability. Malar J 9: 18.

69. Hamadani JD, Fuchs GJ, Osendarp SJ, Khatun F, Huda SN, et al. (2001) Randomized controlled trial of the effect of zinc supplementation on the mental development of Bangladeshi infants. Am J Clin Nutr 74: 381-386.

70. Heyneman SP, Loxley WA (1983) The effect of primary-school quality on academic achievement across twenty-nine high- and low-income countries. Ajs 88: $1162-1194$

71. Bhargava A, Jukes M, Ngorosho D, Khilma C, Bundy DA (2005) Modeling the effects of health status and the educational infrastructure on the cognitive development of Tanzanian schoolchildren. Am J Hum Biol 17: 280-292.

72. Takem EN, Affara M, Amambua-Ngwa A, Okebe J, Ceesay SJ, et al. (2013) Detecting foci of malaria transmission with school surveys: a pilot study in the Gambia. PLoS ONE 8: e67108. doi: 10.1371/journal.pone.0067108.

73. Gitonga CW, Karanja PN, Kihara J, Mwanje M, Juma E, et al. (2010) Implementing school malaria surveys in Kenya: towards a national surveillance system. Malar J 9: 306.

74. Ashton RA, Kefyalew T, Tesfaye G, Pullan RL, Yadeta D, et al. (2011) Schoolbased surveys of malaria in Oromia Regional State, Ethiopia: a rapid survey method for malaria in low transmission settings. Malar J 10: 25.

75. Stevenson J, Stresman G, Gitonga CW, Gillig J, Owaga C, et al. (2013) Reliability of school surveys in estimating geographic variation in malaria transmission in the Western Kenyan highlands. PLoS ONE 8: e77641. doi: 10.1371/journal.pone.0077641. 


\section{Editors' Summary}

Background. Every year, more than 200 million cases of malaria occur worldwide and more than 600,000 people, mostly children living in sub-Saharan Africa, die from this mosquito-borne parasitic infection. Malaria can be prevented by controlling the night-biting mosquitoes that transmit Plasmodium parasites and by sleeping under insecticidetreated nets to avoid mosquito bites. Infection with malaria parasites causes recurring flu-like symptoms and needs to be treated promptly with antimalarial drugs to prevent the development of anaemia (a reduction in red blood cell numbers) and potentially fatal damage to the brain and other organs. Treatment also reduces malaria transmission. In 1998, the World Health Organization and several other international bodies established the Roll Back Malaria Partnership to provide a coordinated global approach to fighting malaria. In 2008, the Partnership launched its Global Malaria Action Plan, which aims to control malaria to reduce the current burden, to eliminate malaria over time country by country, and, ultimately, to eradicate malaria.

Why Was This Study Done? In recent years, many malaria-endemic countries (countries where malaria is always present) have implemented successful malaria control programs and reduced malaria transmission levels. In these countries, immunity to malaria is now acquired more slowly than in the past, the burden of clinical malaria is shifting from very young children to older children, and infection rates with malaria parasites are now highest among schoolaged children. Chronic untreated Plasmodium infection, even when it does not cause symptoms, can negatively affect children's health, cognitive development (the acquisition of thinking skills), and educational achievement. However, little is known about how school-based malaria interventions affect the health of children or their educational outcomes. In this cluster randomized trial, the researchers investigate the effect of intermittent screening and treatment (IST) of malaria on the health and education of school children in a rural area of southern Kenya with low-to-moderate malaria transmission. Cluster randomized trials compare the outcomes of groups ("clusters") of people randomly assigned to receive alternative interventions. IST of malaria involves periodical screening of individuals for Plasmodium infection followed by treatment of everyone who is infected, including people without symptoms, with antimalarial drugs.

What Did the Researchers Do and Find? The researchers enrolled more than 5,000 children aged between 5 and 20 years from 101 government primary schools in Kenya into their 24-month study. Half the schools were randomly selected to receive the IST intervention (screening once a school term for infection with a malaria parasite with a rapid diagnostic test [RDT] and treatment of all RDT-positive children, with or without malaria symptoms, with six doses of artemether-lumefantrine), which was delivered to randomly selected children from classes 1 and 5 (which contained younger and older children, respectively). During the study, $17.5 \%$ of the children in the intervention schools were
RDT-positive at screening on average. The prevalences of anaemia and parasitemia (the proportion of children with anaemia and the proportion who were RDT-positive, respectively) were similar in the intervention and control groups at the 12-month and 24-month follow-up and there was no difference between the two groups in classroom attention scores at the 9-month and 24-month follow-up. The IST intervention also had no effect on educational achievement in the older class but, unexpectedly, appeared to have a negative effect on spelling and arithmetic scores in the younger class.

What Do These Findings Mean? These findings indicate that, in this setting in Kenya, IST as implemented in this study provided no health or education benefits to school children. The finding that the educational achievement of younger children was lower in the intervention group than in the control group may be a chance finding or may indicate that apprehension about the finger prick needed to take blood for the RDT had a negative effect on the performance of younger children during educational tests. The researchers suggest that their failure to demonstrate that the schoolbased IST intervention they tested had any long-lasting health or education benefits may be because, in a low-tomoderate malaria transmission setting, most of the children screened did not require treatment and those who did lived in focal high transmission regions, where rapid re-infection occurred between screening rounds. Importantly, however, these findings suggest that school screening using RDT could be an efficient way to identify transmission hotspots in communities that should be targeted for malaria control interventions.

Additional Information. Please access these websites via the online version of this summary at http://dx.doi.org/10. 1371/journal.pmed.1001594.

- This study is further discussed in a PLOS Medicine Perspective by Lorenz von Seidlein

- Information is available fro $\mathrm{m}$ the World Health Organization on malaria (in several languages); the 2012 World Malaria Report provides details of the current global malaria situation

- The US Centers for Disease Control and Prevention provide information on malaria (in English and Spanish), including a selection of personal stories about children with malaria

- Information is available from the Roll Back Malaria Partnership on the global control of malaria and on the Global Malaria Action Plan (in English and French); its website includes a fact sheet about malaria in Kenya

- MedlinePlus provides links to additional information on malaria (in English and Spanish)

- More information about this trial is available

- More information about malaria control in schools is provided in the toolkit 